Patrick Rainer Brokamp Manhães

\title{
Estudo da fadiga em Policarbonato com o uso da Termografia
}

\section{Projeto de Graduação}

Projeto de Graduação apresentado ao Departamento de Engenharia Mecânica da PUC-Rio

Orientador: Prof. José Luiz de França Freire

Coorientador: Vitor Eboli Lopes Paiva

Rio de Janeiro

Dezembro de 2016 


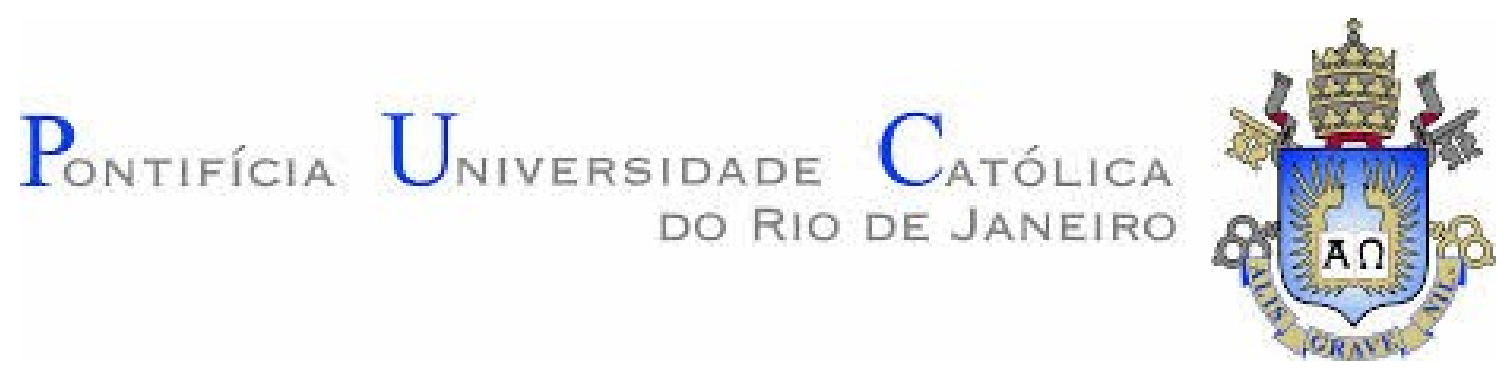

Patrick Rainer Brokamp Manhães

Estudo da fadiga em Policarbonato com o uso da

Termografia

Projeto de graduação

Projeto de Graduação apresentado ao Curso de Engenharia Mecânica do Departamento de Engenharia mecânica da PUC-Rio, como parte dos requisitos necessários à obtenção do titulo de Engenheiro.

\section{Orientador}

Prof. José Luiz de França Freire

Coorientador

Eng. Vitor Eboli Lopes Paiva

Rio de Janeiro

Dezembro 2016 


\section{Agradecimentos}

Primeiramente gostaria de agradecer ao meu orientador, José Luiz de França Freire por ter aceitado me orientar neste projeto e por tornar toda a elaboração possível, me dando acesso ao laboratório. Todo seu ensinamento, tanto teórico como prático, foram fundamentais para realização deste trabalho.

Ao meu coorientador, Vitor Eboli Lopes Paiva, por todo seu auxílio e paciência ao me acompanhar em todos experimentos realizados e por estar sempre disponível para eventuais dúvidas.

Agradeço a minha família, por ter tornado tudo isso possível, por ter me apoiado diariamente desde o início em todas as minhas decisões e por sempre ter acreditado no meu potencial.

Agradeço também a minha namorada, Mariana que sempre esteve ao meu lado nos momentos bons e ruins, me apoiando a cada decisão e tendo paciência com minhas horas de estudo diárias.

A esta universidade, seu corpo docente, direção e administração que me deram a oportunidade de um futuro promissor.

A todos que direta ou indiretamente fizeram parte da minha formação, o meu muito obrigado. A minha formação como profissional não poderia ter sido concretizada sem a ajuda dessas pessoas. Por essa razão, gostaria de dedicar e reconhecer à vocês, minha imensa gratidão. 


\section{Resumo}

Os métodos tradicionais para obter a curva de Wöhler (curva SN) e o limite de fadiga de um material, embora tenham sido desenvolvidos há bastante tempo, são muito eficientes, porém apresentam pontos negativos, como o tempo de duração dos ensaios e custo. Com o avanço da tecnologia, diferentes técnicas foram desenvolvidas e aperfeiçoadas, possibilitando assim métodos menos dispendiosos. Uma dessas técnicas é a termografia aplicada à fadiga, que necessita um tempo mais curto para a realização dos ensaios e um menor número de espécimes, não os levando necessariamente até a falha final.

Nesse trabalho foi estudado e analisado a metodologia desenvolvida por Risitano para medição do limite de fadiga e obtenção da curva SN do material utilizando a termografia. Esses métodos se baseiam na diferença de temperatura entre o espécime analisado e uma referência que está a temperatura ambiente. Quando o material esta sujeito a uma tensão cíclica superior ao seu limite de fadiga ele passa a ter uma resposta termoelástica muito maior do que em níveis de tensões abaixo desse patamar de tensão. Assim é possível correlacionar o comportamento a fadiga do material analisando sua resposta térmica. Neste projeto foi investigada a resistência à fadiga do policarbonato. Este material tem grande importância para aplicações onde se exigem transparência, leveza e resistência estrutural, principalmente grande tenacidade quando comparada a outros materiais polímeros.

Foram realizadas medições utilizando diversos corpos de prova para determinação do limite de fadiga e da curva SN, envolvendo comparações entre os métodos SN tradicional e SN utilizando o procedimento de Risitano. Os valores encontrados foram comparados com a literatura, sendo observadas concordâncias dos resultados.

Foi possível, através de comparações dos resultados obtidos nesse trabalho e dos resultados de outras referências, mostrar que a termografia, com uso do método de Risitano, é uma ferramenta eficiente para o estudo da fadiga, sendo uma excelente alternativa às metodologias tradicionais.

Palavras-chaves: Termografia Infravermelha; Fadiga; Policarbonato; Termoelasticidade; Limite de Fadiga; Curva de Wöhler. 


\begin{abstract}
The traditional method to obtain the Wohler curve (SN curve) and the fatigue limit from a material, though been developed a long time, are very efficient, but they had negative points, with the duration time of the tests and cost. With the technological advancement, different techniques have been developed and improved, giving chance to less expensive methods. One of these techniques is the thermography applied to fatigue, which needs a shorter time for tests realization and a lesser number of specimens, not bringing necessarily to a fracture.
\end{abstract}

It was studied and analyzed the methodology developed by Risitano to measure of the fatigue limit and obtain the SN curve from the material using thermography. This method is based in the temperature difference between the analyzed specimens and a reference at room temperature. When the material is subject to a superior cyclic tension than his fatigue limit, it starts having a thermoelastic answer a lot higher than tensions levels below this tension landing. Like this, is possible to correlate the fatigue material behavior analyzing his thermal answer. In this project, was investigated the resistance to fatigue from the polycarbonate. This material has great resistance to application where needs transparency, lightness and structural resistance, mainly great tenacity when compared to others polymers materials.

It was measured, utilizing several specimens, to determine the fatigue limit and the SN curve, involving comparisons between the traditional SN methods and SN utilizing the Risitano procedure. The values found were compared with literature, been observed similarities in the results.

Was possible, by the comparison from these work's results and from others reference's results, show that thermograph, using the Risitano's method, is an efficient tool to fatigue study, being an excellent alternative to the traditional methodology.

Key-words: Infrared thermography; Fatigue; Polycarbonate; Thermoelasticity; Fatigue Limit; Wöhler curve. 


\section{Lista de figuras}

Figura 2.1: Curva SN típica com evidencia no limite de fadiga $S_{L}$

Figura 2.2: Máquina servo-hidráulica para ensaio de fadiga Instron 8051

Figura 2.3: Curva SN explicativa, [11] e curva SN prática, [1]

Figura 2.4: Dados referentes a um teste segundo o método da escada, [12]

Figura 3.1: Imagem térmica de um transformador de 12V, com detalhe para o aquecimento, temperatura mais elevada, da conexão indicando a provável falha [14].

Figura 3.2: Intensidade da radiação do corpo negro em função do comprimento de onda, em quatro temperaturas[16].

Figura 3.3: Gráfico ilustrativo referente as 3 fases de temperatura

Figura 3.4: Gráfico experimental referente as 3 fases de temperatura.

Figura 3.5: Gráfico $\Delta T$ vs ciclos

Figura 3.6: Gráfico Temperatura de Estabilização vs $\sigma_{e q}$ com interseção das retas indicando o limite de fadiga [5].

Figura 3.7: Procedimento para carregamento com diferentes patamares do espécime para determinação da curva de fadiga do material.

Figura 4.1: Gráfico tensão vs deformação: a) CP de tração CR;

b) Espécime de tração com lados paralelos [5].

Figura 4.2: Corpo de Prova com suas dimensões [5].

Figura 4.3: CP com garras montadas.

Figura 4.4: Foto corpo de prova antes e depois do recozimento visto através de polarioscopio.

Figura 4.5: Corpos de prova preparados e posicionados dentro do

forno para o processo de recozimento.

Figura 4.6: Quadro do forno com came e ponteiro.

Figura 4.7: Quadro com cames e "caminho" percorrido pelo ponteiro de temperatura.

Figura 4.8: Caixa de madeira para isolamento 
Figura 4.9: Imagem do espécime visto a partir da câmera térmica;

a) Sem isolamento térmico [5];b) Com isolamento térmico. 35

Figura 4.10: Câmera Flir A655sc, [19] 36

Figura 4.11: Máquina pneumática usada no meu experimento 37

Figura 4.12: Tela do software de controle da máquina 37

Figura 4.13: Foto com todo o experimento montado com o isolamento

$\begin{array}{ll}\text { térmico aberto para visualização da máquina. } & 37\end{array}$

Figura 5.1: Curva SN medida por termografia para diferentes testes 45

Figura 5.2: Comparação curvas SN 46

Figura 5.3: Média de todas as curvas SN medidas em diferentes

técnicas 46

\section{Lista de tabelas}

Tabela 4.1: Propriedades policarbonato 31

Tabela 4.2: Dimensões dos CP utilizados nos ensaios. 33

Tabela 5.1: Limite de fadiga medido em cada CP. 43

Tabela 5.2: Tensão equivalente e número de ciclos até a falha para cada CP. 


\section{Lista de abreviaturas e siglas}

TIR

Termografia Infravermelha

TSA

Thermoelastic Stress Analysis

DIC

Digital Image Correlation

PSA

Photoelastic Stress Analysis

CP

Corpo de Prova

\section{Lista de símbolos}

$\begin{array}{ll}\mathrm{S} & \text { Amplitude de tensão } \\ \mathrm{N} & \text { Número de ciclos } \\ \mathrm{m} & \text { Expoente de Wöhler } \\ \mathrm{C} & \text { Coeficiente de Wöhler } \\ \mathrm{S}_{\mathrm{L}} & \text { Limite de resistência à fadiga do material } \\ \epsilon & \text { Emissividade } \\ \mathrm{I} & \text { Radiância espectral } \\ \mathrm{h} & \text { Constante de Planck } \\ \mathrm{k} & \text { Constante de Boltzmann } \\ \mathrm{T} & \text { Temperatura } \\ \lambda & \text { Comprimento de onda } \\ \mathrm{c} & \text { Velocidade da luz no vácuo } \\ \alpha & \text { Coeficiente de expansão térmica } \\ \mathrm{T}_{0} & \text { Temperatura de referência } \\ \rho & \text { Densidade do material } \\ \mathrm{C}_{\mathrm{p}} & \text { Calor específico à pressão constante } \\ \mathrm{C}_{\epsilon} & \text { Calor específico a uma deformação constante } \\ \sigma_{\mathrm{ij}} & \text { Tensor de tensão } \\ \epsilon_{\mathrm{ij}} & \text { Taxa de mudança no tensor de deformação } \\ \dot{\mathrm{Q}} & \text { Taxa de produção de calor por unidade de volume. } \\ \delta_{\mathrm{ij}} & \text { Delta de Kronecker }\end{array}$




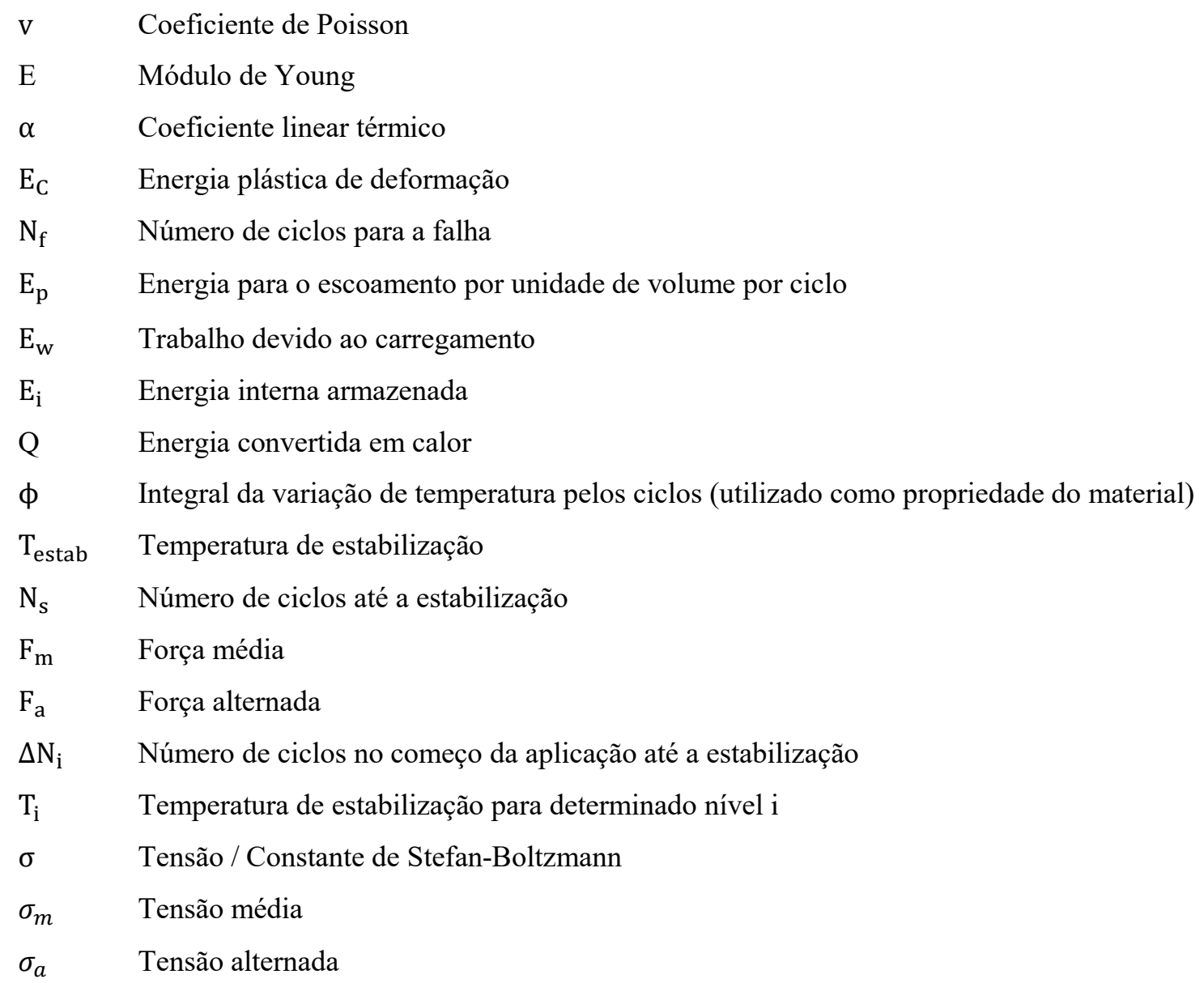




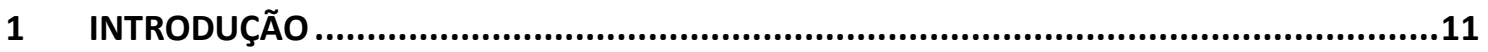

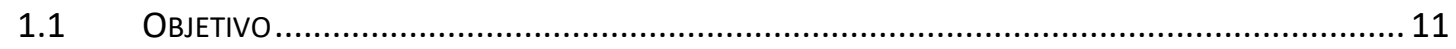

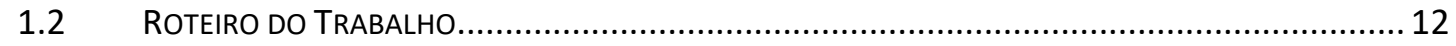

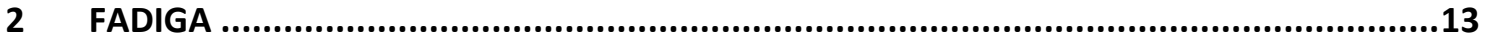

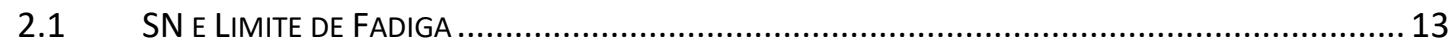

2.1.1 Procedimento Experimental para obter curva SN ............................................. 14

2.1.2 Limite de Fadiga obtido tradicionalmente ............................................................ 17

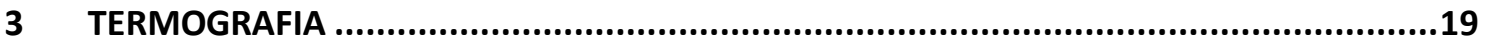

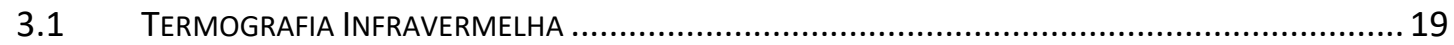

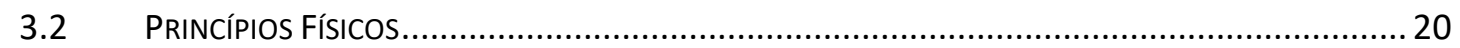

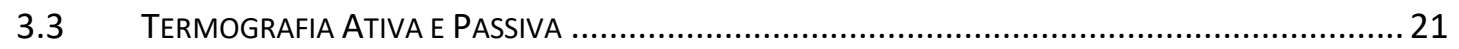

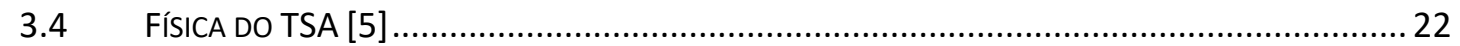

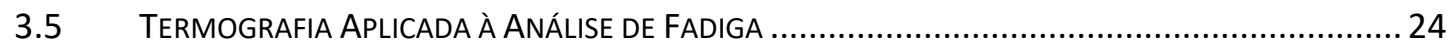

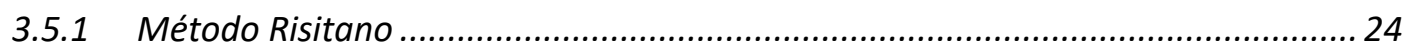

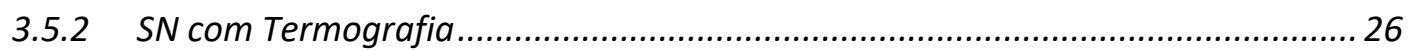

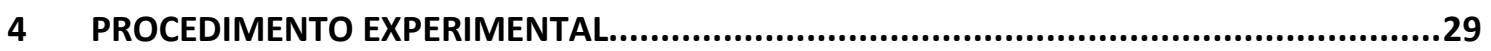

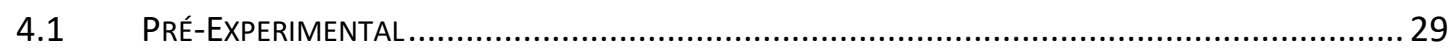

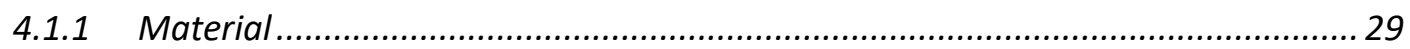

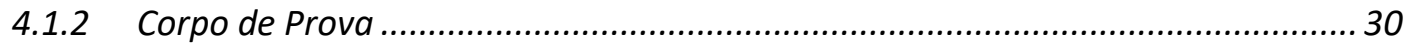

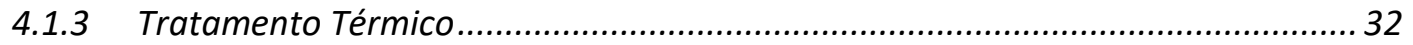

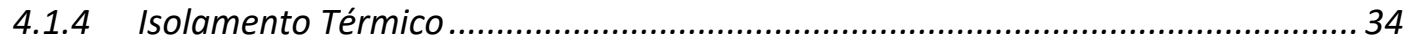

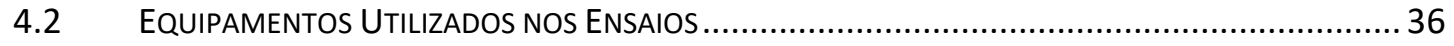

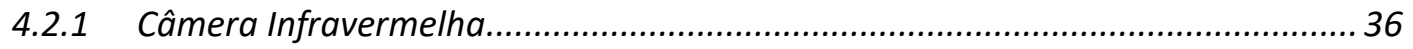

4.2.2 Máquina para Aplicação de Carregamento Cíclico ……........................................ 36

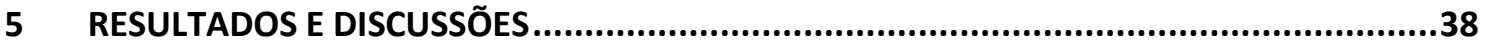

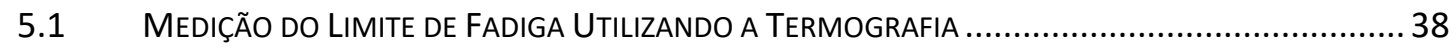

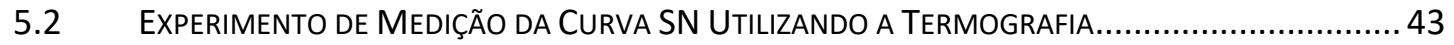

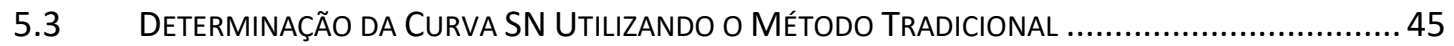

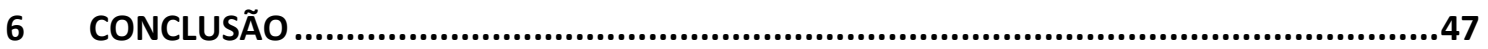

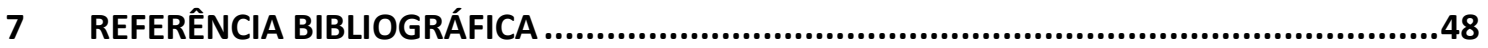




\section{Introdução}

A fadiga é um tipo de falha mecânica que é causada primariamente pela aplicação de cargas repetidas e variadas, cuja principal característica é gerar e/ou propagar paulatinamente uma trinca, até a eventual ruptura do componente estrutural, [1]. Fadiga é de grande relevância em engenharia mecânica, pois grande parte das estruturas mecânicas, durante suas condições de trabalho, são submetidas a cargas cíclicas e a grande maioria das falhas estruturais que ocorrem na prática, envolvem problemas de fadiga. Não há dados brasileiros, mas o custo das falhas estruturais mecânicas já foi estimado em mais de 4\% do PIB da Europa e dos Estados Unidos, [2].

\subsection{Objetivo}

Um dos métodos mais usados para dimensionamento de fadiga é conhecido como método de Wöhler ou método SN [1], entretanto esse método é dispendioso e requer uma grande quantidade de tempo para obtenção de resultados. Todavia existem outros métodos que são capazes de acelerar esse processo, sendo um deles chamado de método de Risitano [3;4], que utiliza a termografia para determinar a curva SN e o limite de fadiga do material.

Neste trabalho será estudada a aplicabilidade do método de Risitano ao estudo da fadiga em policarbonato. Esse método tem como pontos positivos a agilidade e o baixo custo para análise do comportamento à fadiga. $\mathrm{O}$ policarbonato foi o material escolhido, pois tem grande importância na engenharia, com diversas aplicações e é frequentemente usado em aplicações de estresse relativamente alto, o que torna importante o seu estudo. Como não temos muitos resultados de SN pelo método de Risitano, a não ser aqueles encontrados em [5], decidi fazer todo o estudo em policarbonato 


\subsection{Roteiro do Trabalho}

Esse trabalho foi dividido em 6 capítulos, um que apresenta considerações gerais, quatro de desenvolvimento e um de conclusões e recomendações. A seguir são indicados os aspectos mais importantes de cada um deles:

O Capítulo 1 tem como objetivo introduzir o tema deste trabalho, fazendo com que o leitor entenda um pouco mais sobre o que foi estudado e desenvolvido durante sua realização.

O Capítulo 2 apresenta e introduz fenômeno da fadiga, suas características e metodologias para sua análise.

No Capítulo 3 é apresenta a técnica da termografia, explicando seus princípios físicos e sua aplicabilidade ao estuda da fadiga. É apresentado também o método de Risitano que correlaciona a temperatura na superfície de um espécime sujeito a diferentes carregamentos cíclicos com seu comportamento dinâmico para determinação do limite de fadiga e da sua curva SN.

O Capítulo 4 trata do procedimento experimental para obtenção e análise de resultados. No procedimento pré-experimental é definido o material de utilizado, policarbonato, a geometria dos CPs trabalhados, o tratamento de alívio de tensões realizado e o isolamento térmico empregado para aprimorar as medições. No procedimento experimental são apresentados os equipamentos utilizados durante os ensaios: câmera térmica e máquina pneumática para aplicação de esforços cíclicos.

No Capítulo 5 são analisados e discutidos os resultados medidos durante os diferentes ensaios. Foram determinados o limite de fadiga e a curva SN do policarbonato utilizando a metodologia de Risitano, apresentada no Capítulo 3.

O Capítulo 6 apresenta as conclusões e recomendações sobre os resultados obtidos no desenvolvimento do presente trabalho. 


\section{Fadiga}

Fadiga, em geral, é um fenômeno complexo que é caracterizado pela redução gradual da capacidade de um comportamento estrutural de suportar cargas cíclicas. $\mathrm{O}$ dano por fadiga é um processo cumulativo resultante da aplicação de um grande número de ciclos de tensões. A amplitude dos ciclos de tensão aplicada pode ser relativamente baixa em relação a tensão de escoamento do material, mas o grande número de aplicações repetidas pode levar à fratura do material. A fadiga é caracterizada pela geração e/ou propagação gradativa de uma trinca até uma possível ruptura. Assim, a trinca é gerada pela gama das deformações $\Delta \epsilon$ ou das tensões $\Delta \sigma$ atuante no ponto critico da peça. Ela acontece nesse ponto da peça, onde é máxima a razão entre as tensões reais de trabalho e a resistência a fadiga, a qual depende muito dos detalhes da geometria do material naquele ponto. Portanto, os modelos do trincamento por fadiga em geral podem ser baseados em análises locais das solicitações e da resistência no entorno do ponto critico e não na análise global da peça.

Embora fora do escopo deste trabalho, entretanto tratada em [5] para espécimes de policarbonato, deve-se, à título de complementaridade, mencionar que a propagação de trincas é controlada pela gama do fator de intensidade de tensões $\Delta K$, diferente da iniciação de trincas que é controlado pela gama de tensões. A resistência a propagação

de trincas é medida pela sua taxa de crescimento por ciclo de carga, $\frac{d a}{d N}$ em $\frac{m}{c i c l o}$, que é dependente da gama $\Delta K$ do fator de intensidade de tensões. Sabemos que a maioria das falhas mecânicas que ocorrem são causadas por fadiga, e é de extrema importância controlar e evitar essas falhas, pois elas podem levar a acidentes catastróficos.

\subsection{SN e Limite de Fadiga}

O método mais usado para caracterização da resistência à fadiga é chamado de método de Wöhler ou método SN. Ele é usado para evitar o trincamento à fadiga ou para prever as vidas longas associadas às cargas elásticas. O método correlaciona a amplitude das tensões cíclicas que atuam em um ponto crítico e o número de ciclos de carga necessários para iniciar uma trinca. A curva SN explica graficamente ou por meio de uma equação essa correlação e pode ser usado para prever o número de ciclos que o espécime, consegue suportar determinada tensão alternada, antes de trincar. 
A curva SN é expressa pela Equação 2.1.

$$
N S^{m}=C
$$

onde, $\mathrm{N}$ é o número ciclos até a falha ocorrer, $\mathrm{S}$ é a amplitude de tensão $\left(S=\sigma_{a}=\frac{\Delta \sigma}{2}\right)$, m e C são as constantes do material conhecidas como o expoente de Wöhler e o coeficiente de Wöhler. A curva SN segue a forma mostrada na figura 2.1.

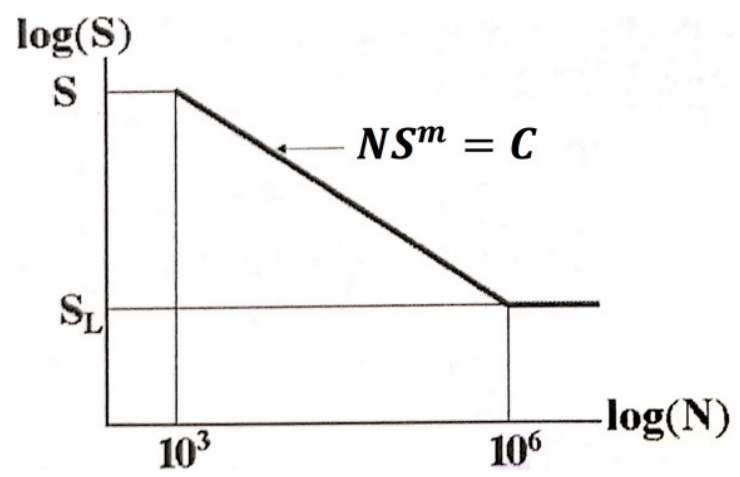

Figura 2.1: Curva SN típica com evidencia no limite de fadiga $S_{L}$

Cada ponto dessa curva corresponde ao número de ciclos necessários antes de ocorrer a falha em um espécime. Pode-se perceber que no final da curva ela tende a ficar horizontal e o valor de S para esse ponto corresponde ao limite de resistência a fadiga $S_{L}$ a partir de uma vida longa $N_{L}{ }^{1}$. Este limite significa que tensões de amplitude menores que $S_{L}$ não causam dano nos CPs, podendo assim ter vida infinita à fadiga. Fazendo uma breve análise visual da curva pode-se entender o porque de um teste de fadiga ser tão demorado, visto que a quantidade de ciclos para alcance do patamar é sempre muito alta.

\subsubsection{Procedimento Experimental para obter curva SN}

A curva SN é obtida experimentalmente a partir de diversos ensaios em máquinas servo-hidráulicas ou de flexão plana ou rotativa em que se aplicam cargas para simular condições reais de serviço. Máquinas servo-hidráulicas, como da Figura 2.2, são muito sofisticadas, porém seu uso é necessário.

\footnotetext{
${ }^{1}$ Nem todos os materiais apresentam este patamar horizontal ou limite de resistência à fadiga para vida infinita.
} 


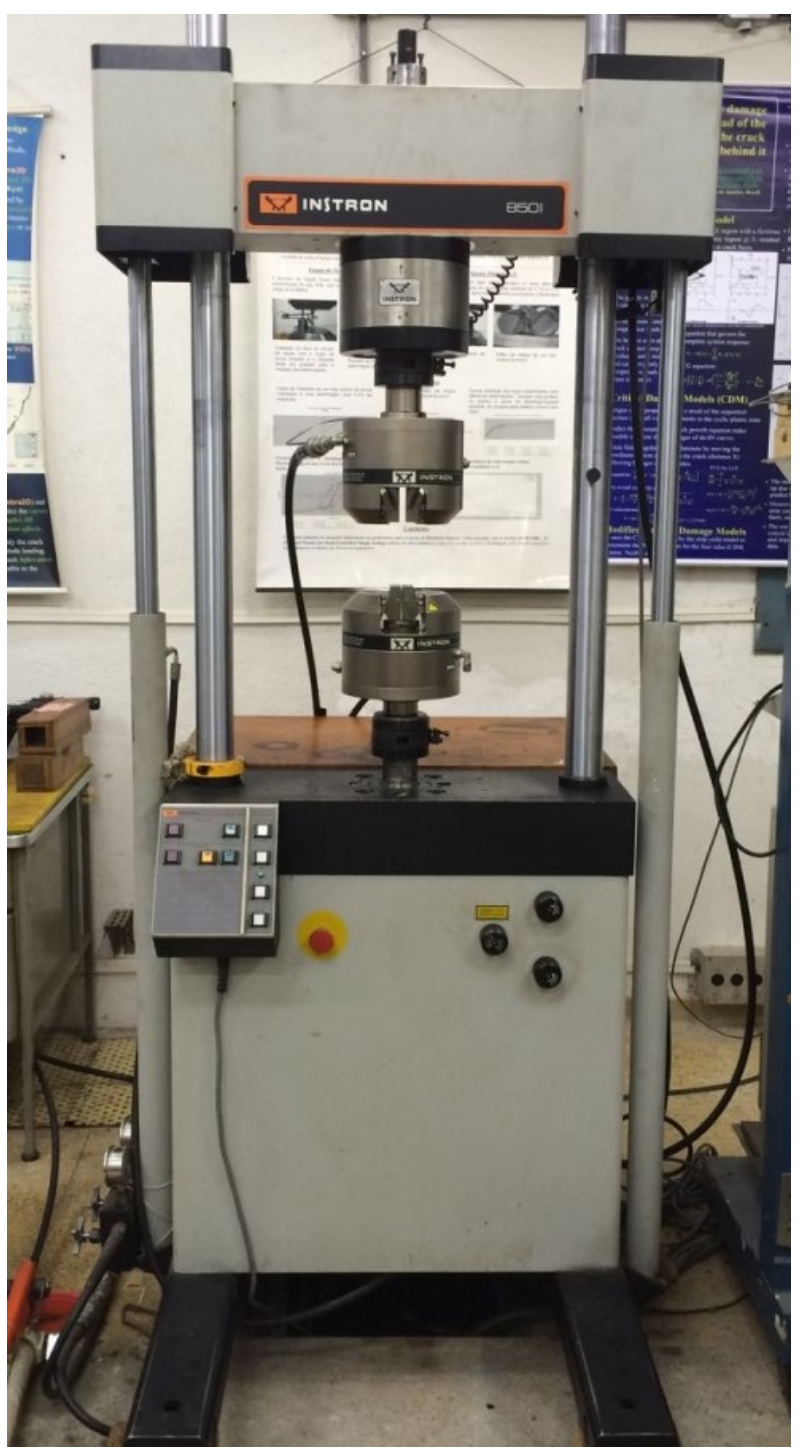

Figura 2.2: Máquina servo-hidráulica para ensaio de fadiga Instron 8051

As máquinas de ensaio de fadiga são constituídas por um sistema de aplicação de cargas, que nos permite alterar a intensidade e o sentido do esforço, além de registrar o número de ciclos aplicados. Assim que o corpo de prova se rompe o teste é interrompido. O ideal é que faça-se vários testes, com diferentes cargas e com cargas iguais, para obter-se mais pontos nos gráficos. Para uma mesma tensão, pode-se obter resultados diferentes, então por isso a realização de vários testes com mesma carga é importante, [6].

A abordagem convencional de ensaio $\mathrm{SN}$ requer uma série de testes a serem conduzidos, sob diferente nível de tensão, preferencialmente com replicação, para determinar a curva SN. Usando esta abordagem, um intervalo na vida de fadiga para cada nível de tensão pode ser estimado para produzir uma família de curvas SN com vários níveis de probabilidade. 
O uso de testes múltiplos no mesmo conjunto de níveis de carga permite um meio para descrever essa faixa na vida de fadiga usando uma distribuição de probabilidade [7]. Esta distribuição permite então uma estimativa da média e desvio padrão para a vida de fadiga para qualquer nível de carga dentro do intervalo de dados. Os detalhes de como estabelecer a curva $\mathrm{SN}$ usando um modelo matemático são geralmente diretos para modelos simples. Em particular, [8] descreve a análise estatística de dados de fadiga SN. Quando todos os espécimes de fadiga falham, o método mais comum para determinar os parâmetros da curva SN é usar mínimos quadrados ordinários, o mesmo método comumente usado em ajustes de curva de dados de engenharia para os últimos 200 anos desde que foi popularizado por Gauss [6; 7]. Este método tem um sério inconveniente, no entanto. Nomeadamente, os runouts ${ }^{2}$ [9] não podem ser usados uma vez que um tempo real de falha não é conhecido. Assim, a diferença entre a curva de melhor ajuste e o ponto de dados real não pode ser calculado por runouts. Portanto, a análise SN convencional usando mínimos quadrados ordinários (ou uma abordagem similar) deve excluir os dados do teste runout. Para testes de ciclo elevado, há muitas vezes um grande número de espécimes que não falham no tempo de teste atribuído, uma vez que não é viável testar cada espécime até falha, pois o teste é de longa duração. No entanto, se todos (ou a grande maioria) dos testes forem executados até a falha, a abordagem S-N convencional permitiria uma representação gráfica da resistência à fadiga associada a um número especificado de ciclos, bem como o limite de fadiga, se este existir [10].

Os resultados do ensaio de fadiga são apresentados em um gráfico de tensão por número de ciclos, como mostrado na Figura 2.3, [11].
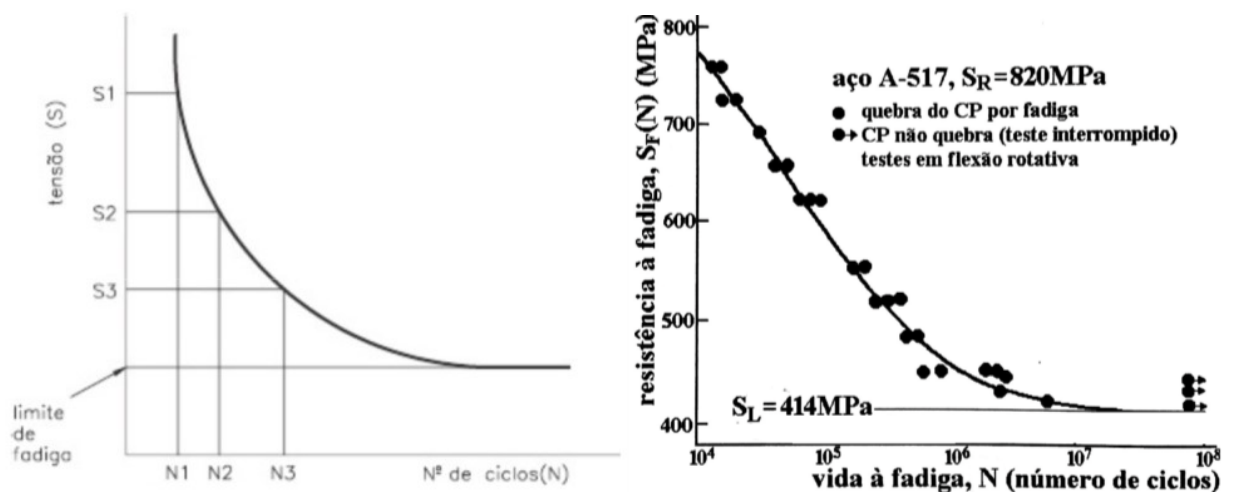

Figura 2.3: Curva SN explicativa, [11] e curva SN prática, [1]

\footnotetext{
${ }^{2}$ Runouts são espécimes que não falham antes da conclusão do ensaio.
} 
Supondo que, para uma determinava tensão S1 o corpo de prova se rompa com N1 ciclos, e para uma tensão S2 se rompa em N2 e assim por diante, constrói-se o diagrama SN. Conforme se diminui a tensão aplicada, o corpo de prova tem uma maior resistência.

\subsubsection{Limite de Fadiga obtido tradicionalmente}

O método da "escada", staircase method, é um método discreto que varia em etapas. Em oposição ao método convencional de análise $\mathrm{SN}$, a resposta desse método não considera realmente um número de ciclos para a falha, mas sim os testes são tratados de uma maneira "passa ou falha", como mostrado na Figura 2.4.

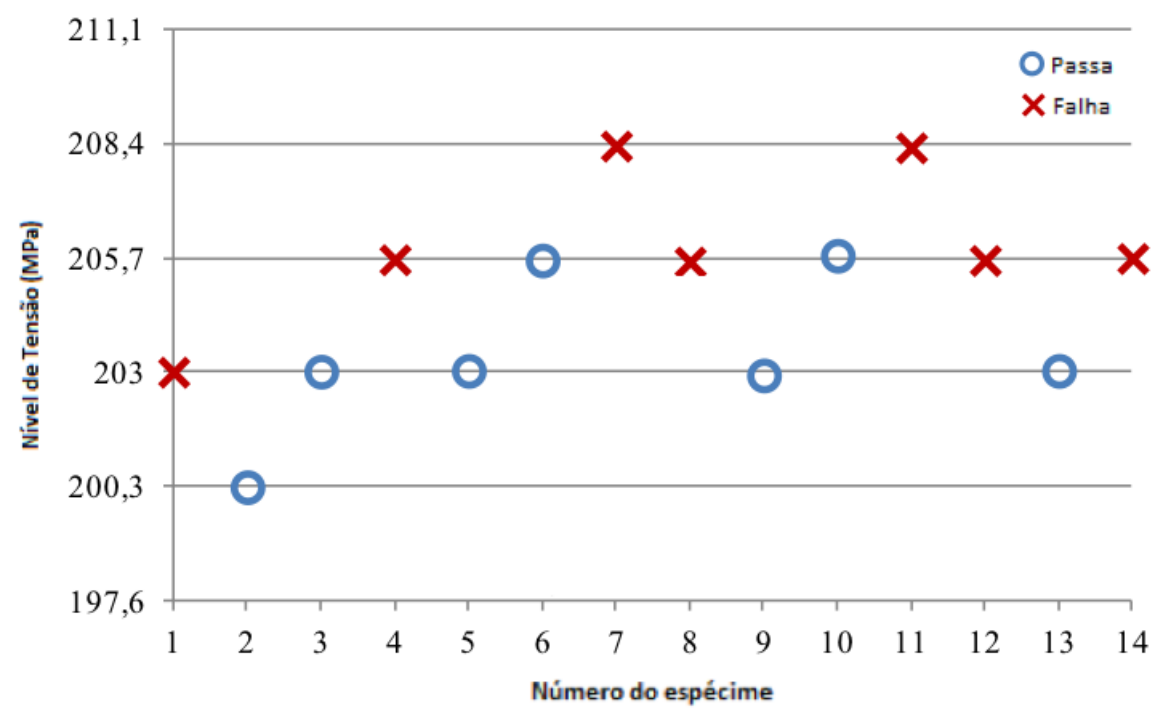

Figura 2.4: Dados referentes a um teste segundo o método da escada [12] para $\mathrm{N}>2 \cdot 10^{6} 3$

O método da escada foi primeiramente proposto por Dixon e Mood [13], onde os espécimes são testados sequencialmente, com o primeiro espécime sendo testado a um nível de tensão inicial definido arbitrariamente a partir da experiência ou dados SN preliminares. O nível de tensão do próximo espécime é aumentado ou diminuído dependendo se o espécime anterior falhou ou não. Esse processo é continuado até todos os corpos de prova necessários sem utilizados.

Tipicamente, o tamanho do passo entre os níveis de tensão é mantido constante (aproximadamente igual ao desvio padrão do limite de fadiga), em que as estatísticas de

3 Por Marco Vinicio Guamán Alarcón “Fatigue limit assessment of a low carbon steel using Dixon’s upand-down method and infrared thermography" 
Dixon e Mood podem ser aplicadas diretamente para estimar a média e o desvio padrão do limite de fadiga. Embora o desvio padrão do limite de fadiga seja uma das incógnitas, Dixon chama a atenção que não é muito importante se o intervalo é realmente incorreto em relação ao desvio padrão real de até $50 \%$ para estimativas da força média de fadiga.

A principal vantagem do método da escada é sua eficiência, originalmente Dixon e Mood indicaram que esse método requer em torno de 40 a 50 espécimes para resultados acurados.

Outra abordagem para obter-se limite de fadiga é a realização de testes acelerados. O ensaio do esforço acelerado inclui os ensaios em que o nível de tensão aumenta durante o ensaio de um espécime para garantir que a falha ocorra em um número razoável de ciclos. Essa abordagem difere da anterior, pois agora o nível de tensão é variável durante o ensaio, enquanto o outro era fixo, [10].

A seguir será abordado um pouco do tema termografia, para que seja possível compreender o método de análise de fadiga usado no presente trabalho. 


\section{Termografia}

A termografia é uma técnica que permite mapear um corpo ou uma região através de uma câmera térmica, com a intenção de distinguir áreas de diferentes temperaturas, sendo, portanto, uma técnica que permite a visualização artificial da luz dentro do espectro infravermelho. Em geral, pode ser dividida em dois tipos, a termografia ativa e a passiva.

\subsection{Termografia Infravermelha}

Um corpo, em qualquer temperatura, emite radiação, algumas vezes denominada radiação térmica. As características desta radiação dependem da temperatura e das propriedades do corpo. Todos os objetos com temperatura maior que $0 \mathrm{~K}$ emitem radiação infravermelha. Em temperaturas baixas, os comprimentos de onda da radiação térmica estão, principalmente, na região do infravermelho e, por isso, não são percebidas pela vista humana. Quando a temperatura do corpo se eleva, ele principia a brilhar com coloração vermelha. Em temperaturas suficientemente elevada, o corpo parece de cor branca. Na foto abaixo (Figura 3.1) percebe-se uma cor diferente para cada nível de temperatura. $\mathrm{O}$ estudo da radiação térmica mostra que ela consiste em uma distribuição continua de comprimentos de onda, que vão do infravermelho, passam pelo visível e chegam à parte ultravioleta do espectro.

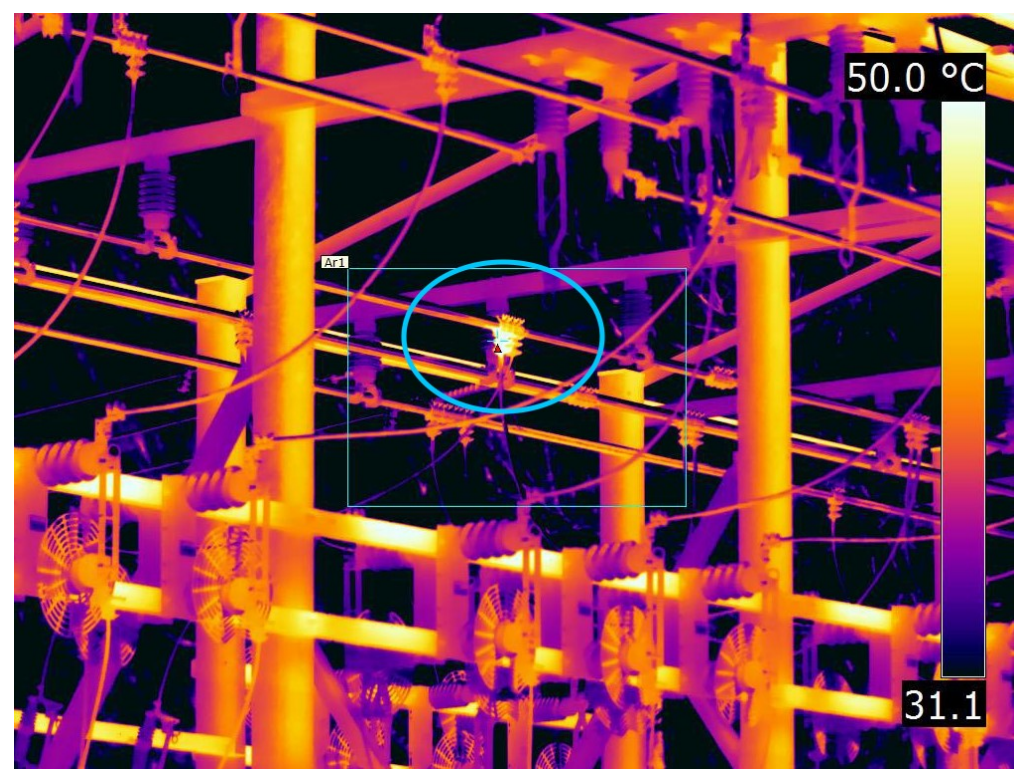

Figura 3.1: Imagem térmica de um transformador de $12 \mathrm{~V}$, com detalhe para o aquecimento, temperatura mais elevada, da conexão indicando a provável falha [14]. 
Do ponto de vista clássico, a radiação térmica se origina de partículas carregadas, aceleradas nas vizinhanças da superfície do corpo; estas cargas emitem radiação de maneira muito parecida com uma antena. As cargas com agitação térmica podem ter uma distribuição de acelerações, o que explicaria o espectro continuo de radiação. Ao longo do tempo, tornou-se evidente que a teoria clássica da radiação térmica era inadequada e o problema fundamental era o entendimento da distribuição de comprimentos de ondas observada na radiação emitida por um corpo negro. Por definição, um corpo negro é um sistema ideal que absorve toda a radiação incidente sobre ele. Esse corpo negro é introduzido como um emissor ideal, visto que nenhuma superfície pode emitir mais radiação que um corpo negro na mesma temperatura, [15].

O conceito de que um corpo negro é um absorvedor perfeito e emissor de energia radiante, vem da lei da radiação térmica de Kirchhoff, que afirma que a emissividade $(\varepsilon)$ de um corpo é igual à sua capacidade de absorção, e ela se define como a razão entre a radiação emitida pela superfície e a radiação emitida por um corpo negro a uma mesma temperatura.

\subsection{Princípios Físicos}

A Lei de Planck para radiação de corpo negro exprime a radiância espectral em função do comprimento de onda e da temperatura do corpo negro e é definida pela equação (3.1)

$$
I(\lambda, T)=\frac{2 \pi h c^{2}}{\lambda^{5}\left(e^{\frac{h c}{\lambda k T}}-1\right)}
$$

onde, $\mathrm{k}$ é a constante de Boltzmann (1.381 x $\left.10^{-23} \frac{\mathrm{m}^{2} \mathrm{~kg}}{\mathrm{~s}^{2} \mathrm{~K}}\right)$, c é a velocidade da luz no vácuo $\left(299792458 \frac{\mathrm{m}}{\mathrm{s}}\right)$ e h é a constante de Planck $\left(6,626 \times 10^{-34} \mathrm{~J} \cdot \mathrm{s}\right)$ que pode ser calculada para ajustar-se aos dados experimentais [5].

A Figura 3.2 mostra os dados experimentais da distribuição de energia na radiação do corpo negro, em quatro temperaturas diferentes. A energia irradiada varia com o comprimento de onda e com a temperatura. Quando a temperatura do corpo negro se eleva, a quantidade total de energia emitida aumenta. Também com a elevação da temperatura, o pico da distribuição se desloca para os comprimentos de onda menores. 


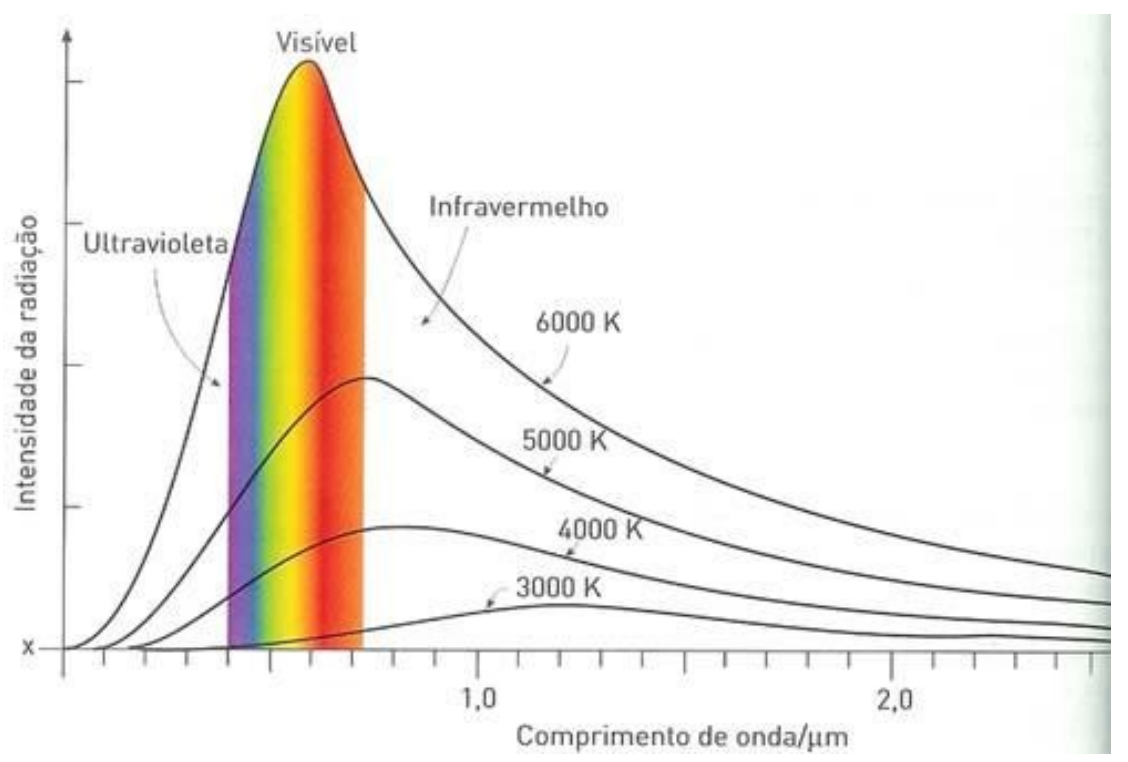

Figura 3.2: Intensidade da radiação do corpo negro em função do comprimento de onda, em quatro temperaturas[16].

A Lei de Stefan-Boltzmann (mais conhecida como Lei de Stefan) estabelece que a energia total radiada por unidade de área superficial de um corpo negro na unidade de tempo, é diretamente proporcional à quarta potência da sua temperatura termodinâmica $\mathrm{T}$.

Para obter a emitância total de um corpo negro integra-se a equação (3.1) para todos os comprimentos de onda e então obtém-se a equação (3.2).

$$
I=\int_{\lambda} I(\lambda, T)=\sigma T^{4}
$$

onde, $\sigma$ é a constante de Stefan-Boltzmann $\left(5,670 \times 10^{-8} \frac{W}{m^{2} K^{4}}\right)$.

\subsection{Termografia Ativa e Passiva}

A termografia pode ser divida em dois tipos, termografia ativa e passiva. A termografia ativa consiste em medir os efeitos de uma fonte de calor sobre um objeto. Normalmente é usada para medir diferenças nas taxas de aquecimento, que podem ser usadas para detectar características que não geram calor por si só. $\mathrm{Na}$ engenharia mecânica, a termografia ativa é muito usada na técnica de termografia pulsada que é usada para avaliação não destrutiva de materiais. 
Ao contrário da termografia ativa, a passiva não necessita de uma fonte de calor, como o nome já sugere. Ela se baseia em variações de temperatura já existentes no objeto analisado, geralmente causadas por geração de calor dentro dele mesmo. A técnica de termografia passiva tem diversas aplicações no dia-a-dia e uma delas está no uso da técnica chamada Thermoelastic Stress Analysis (TSA), mas o presente trabalho se refere a termografia ativa, então o método será explicado como curiosidade, mas sem resultados experimentais.

\subsection{Física do TSA [5]}

Quando um material sólido é submetido a tensão trativa, sua temperatura varia ligeiramente e, quando uma tensão de compressão é aplicada, a temperatura varia no sentido oposto na mesma proporção.

A mudança na temperatura causada pelo efeito termoelástico é proporcional a soma das tensões principais atuando no corpo. A equação que descreve esse fenômeno é a equação (3.3):

$$
\Delta \mathrm{T}=-\frac{\alpha \mathrm{T}_{0}}{\rho c_{\mathrm{p}}}\left(\Delta \sigma_{1}+\Delta \sigma_{2}\right)
$$

onde, $\alpha$ é o coeficiente de expansão térmica, $T_{o}$ é a temperatura de referência, $\rho$ é a densidade do material, $c_{p}$ é o calor especifico a pressão constante e $\sigma_{1} e \sigma_{2}$ são as tensões principais.

Uma dedução simples da equação 3.3 será mostrada aqui, enquanto os argumentos termodinâmicos podem ser vistos em [17].

Uma pequena mudança de temperatura em um corpo depende do seu estado de tensão, dos esforços que estão sendo aplicados e da troca de calor que ocorre dentro do sólido [18].

$$
\dot{T}=\frac{T_{0}}{\rho C_{\epsilon}} \frac{\partial \sigma_{i j}}{\partial T} \dot{\epsilon_{l j}}+\frac{\dot{Q}}{\rho C_{\epsilon}}
$$

onde, $T_{0}$ é a temperatura de referência, $\rho$ é a densidade do material, $C_{\epsilon}$ é o calor especifico a uma deformação constante, $\sigma_{i j}$ é o tensor de tensão, $\epsilon_{i j}$ é a taxa de mudança no tensor de deformação e $\dot{Q}$ é a taxa de produção de calor por unidade de volume. 
Em TSA, a abordagem padrão é aplicar uma carga cíclica ao espécime em uma frequência na qual não ocorre condução de calor entre os pontos do corpo, tornando possível negligenciar o segundo termo da equação 3.4. Portanto, é seguro dizer que o sensor ira apenas medir a variação da temperatura da superfície e que a relação tensãodeformação-temperatura para um material isotrópico em condições de tensão plana pode ser usada.

$$
\sigma_{i j}=2 \mu \epsilon_{i j}+\left(\lambda \epsilon_{k k}-\beta \delta T\right) \delta_{i j}
$$

onde, $\delta_{\mathrm{ij}}$ é o delta de Kronecker e,

$$
\boldsymbol{\mu}=\frac{\mathbf{E}}{2(1+\mathrm{v})} \boldsymbol{\lambda}=\frac{\mathbf{v E}}{(1+\mathrm{v})(1-2 \mathrm{v})} \boldsymbol{\beta}=(3 \boldsymbol{\lambda}+2 \boldsymbol{\lambda}) \boldsymbol{\alpha}
$$

onde, $v$ é o coeficiente de Poisson, E é o modulo de Young e $\alpha$ é o coeficiente linear térmico.

Derivando a equação 3.5 em função de $\mathrm{T}$, e assumindo que a constante linear não varia com a temperatura:

$$
\frac{\partial \sigma_{i j}}{\partial T}=-\beta \delta_{i j}
$$

Então, substituindo a equação 3.7 em 3.4:

$$
\dot{T}=-\frac{T_{0 \beta}}{\rho C_{\epsilon}} \epsilon_{k k}
$$

Usando a equação 3.5 e 3.6 :

$$
\dot{T}=-\alpha\left[\frac{T_{0}}{\rho C_{\epsilon}}+\frac{1-2 v}{3 \alpha^{2} E}\right] \sigma_{k k}
$$

Sabendo que $C_{\epsilon}$ pode ser escrito em função de $C_{p}$ :

$$
C_{\epsilon}=C_{p}-\frac{3 E \alpha T_{0}}{\rho(1-2 v)}
$$

E, aplicando a equação 3.10 em 3.9 e integrando-a, obtêm-se a equação 3.3. 


\subsection{Termografia Aplicada à Análise de Fadiga}

\subsubsection{Método Risitano}

A metodologia proposta por La Rosa e Risitano, [3] diz que, analisando a temperatura da superfície externa durante aplicação de um carregamento cíclico, é possível avaliar o comportamento dinâmico do componente e determinar o limite de fadiga do material. Essa metodologia não precisa de qualquer máquina de ensaio particular e permite obter resultados confiáveis utilizando um número muito limitado de espécimes, em um curto espaço de tempo.

É sabido que quando o material é submetido a um carregamento sua temperatura varia (Efeito Termoelástico). No caso de um carregamento acima do limite de fadiga, essa variação de temperatura é significativa e pode ser observada por diferentes métodos experimentais.

Quando o componente é ciclicamente carregado, o gráfico da temperatura pelo número de ciclos tem forma similar a Figura 3.3 e 3.4 .

A fase 1 é referente ao aumento de temperatura no início da aplicação do carregamento. A taxa de aquecimento é proporcional à carga aplicada, assim carregamentos mais elevados apresentam maiores taxas de aquecimento. A fase 2 é referente à temperatura estabilizada para o carregamento aplicado. A fase 3 é referente ao aumento súbito da temperatura, quando o material esta na eminência da fratura.

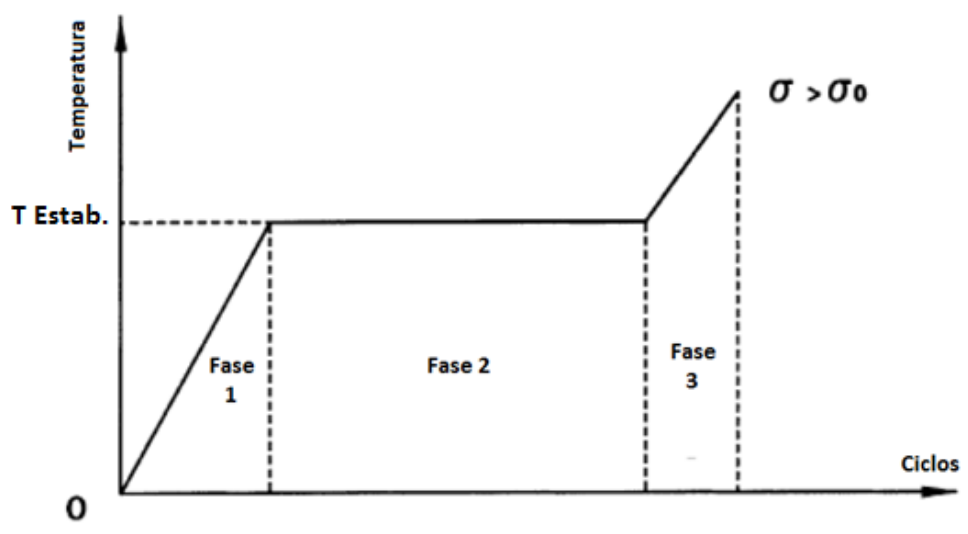

Figura 3.3: Gráfico ilustrativo referente as 3 fases de temperatura 


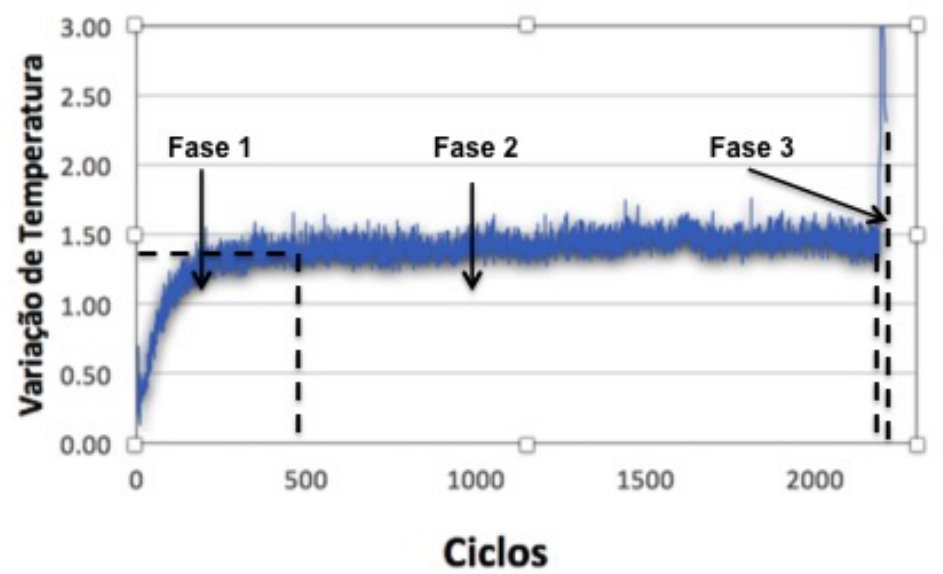

Figura 3.4: Gráfico experimental referente as 3 fases de temperatura.

O conceito do método é medir a diferença estabilizada entre as temperaturas, do CP onde está sendo aplicada a carga e a de referência (ambiente), para diferentes níveis de carregamento, partindo da menor para a maior carga. A Figura 3.5 mostra a forma do gráfico.

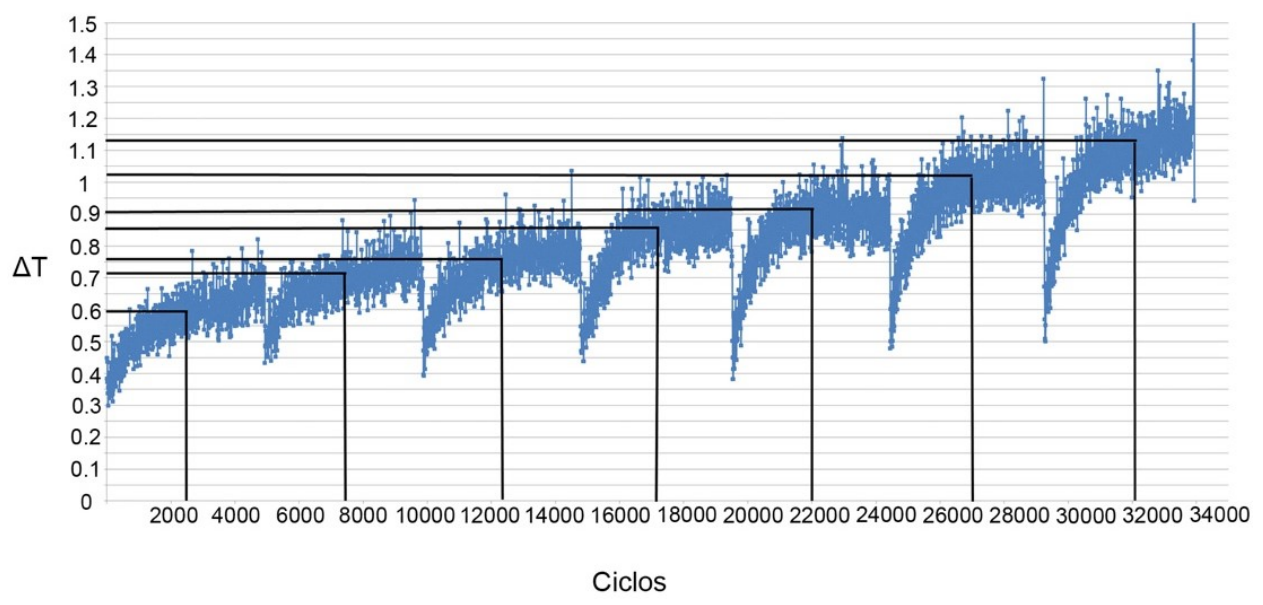

Figura 3.5: Gráfico $\Delta T v s$ ciclos

Cada nível de tensão contem uma temperatura de estabilização própria. Após sua determinação é traçado um novo gráfico, temperatura de estabilização vs tensão equivalente de Goodman, para cada patamar de tensão.

O método de Risitano extrapola os dados usando duas linhas diferentes, onde a primeira linha contém os pontos onde a tensão aplicada está abaixo do limite de fadiga do material e a segunda linha os pontos acima do limite. O limite de fadiga é determinado pela interseção dessas duas linhas, como mostrado na Figura 3.6. 


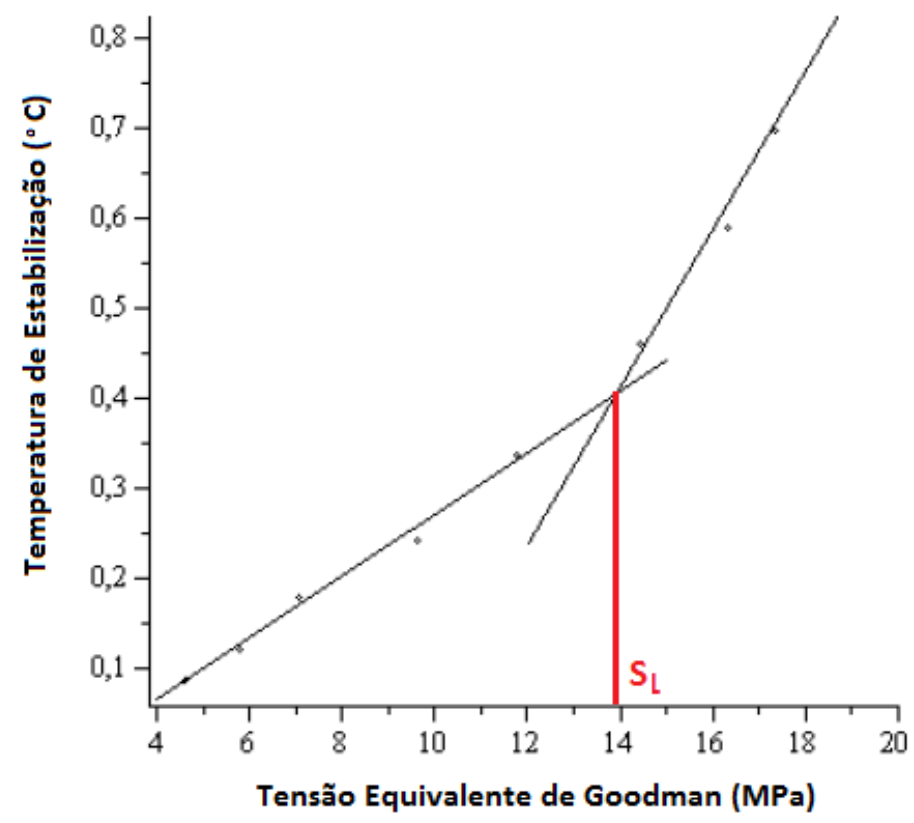

Figura 3.6: Gráfico Temperatura de Estabilização vs $\sigma_{e q}$ com interseção das retas indicando o limite de fadiga [5].

\subsubsection{SN com Termografia}

Risitano et al. [4] propôs um método, baseado na metodologia para medição do limite de fadiga, para determinar a curva $\mathrm{SN}$ do material usando a termografia. $\mathrm{O}$ conceito desse método correlaciona a energia plástica de deformação $\left(E_{C}\right)$ com a falha do material, que pode ser descrita segundo a Equação 3.11:

$$
E_{C}=\int_{0}^{N_{f}} E_{p} d N
$$

onde $E_{C}$ é o montante de energia de deformação micro plástica para falha por unidade de volume (uma propriedade do material), $N_{f}$ é o número de ciclos para a falha e $E_{p}$ é a energia para o escoamento por unidade de volume por ciclo.

Utilizando o balanço de energia tem-se, a Equação 3.12:

$$
E_{W}=E_{i}+Q
$$


onde $E_{w}$ é o trabalho devido ao carregamento, $E_{i}$ é a energia interna armazeda e Q é a energia convertida em calor. Assumindo que $E_{i}$ é pequeno se comparado a $\mathrm{Q}$ pode-se considerar $E_{w}$ proporcional a $E_{p}$, e assim a equação 3.13 pode ser reescrita como:

$$
E_{c}=\int_{0}^{T_{f}} d Q
$$

Para pequenas variações de temperatura (menores que 100K, implicando em pequenas frequências de carregamento), o calor transferido do espécime para o ambiente pode ser considerado igual a diferença de temperatura, $(\Delta T)$. Dessa maneira que pode ser avaliado utilizando um parâmetro $\phi$, que é a integral da variação de temperatura pelos ciclos, como mostrado na curva da Figura 3.3 e 3.4, segundo a equação 3.14 :

$$
\phi=\int_{0}^{N_{f}} \Delta T d N
$$

ou, aproximadamente, a soma das áreas abaixo da curva, negligenciando a fase 3 que em geral é rápida.

$$
\phi=\frac{T_{e s t a b} * N_{s}}{2}+T_{e s t a b} *\left(N_{f}-N_{s}\right)=c t e
$$

onde, $T_{\text {estab }}$ é a temperatura de estabilização, $N_{s}$ é o número de ciclos até a estabilização e $N_{S}$ é o número de ciclos até a falha. $\phi$ é utilizado como uma propriedade do material, cujo o valor critico leva o espécime à falha por fadiga. Na referência [5], foi determinado o valor de $\phi$ igual a $28905{ }^{\circ} \mathrm{C}$ ciclo, para um carregamento constante com $F_{m}=1637 \mathrm{~N}$ e $F_{a}=477 \mathrm{~N}$, resultando em uma tensão equivalente de Goodman igual a $21.25 \mathrm{MPa}$ e uma vida total medida $\left(N_{f}\right)$ de 24250 ciclos.

A Figura 3.7 ilustra como a medição é realizada, onde o espécime é carregado em patamares com diferentes níveis de tensão apresentando para cada um deles diferentes $N_{S}$. 


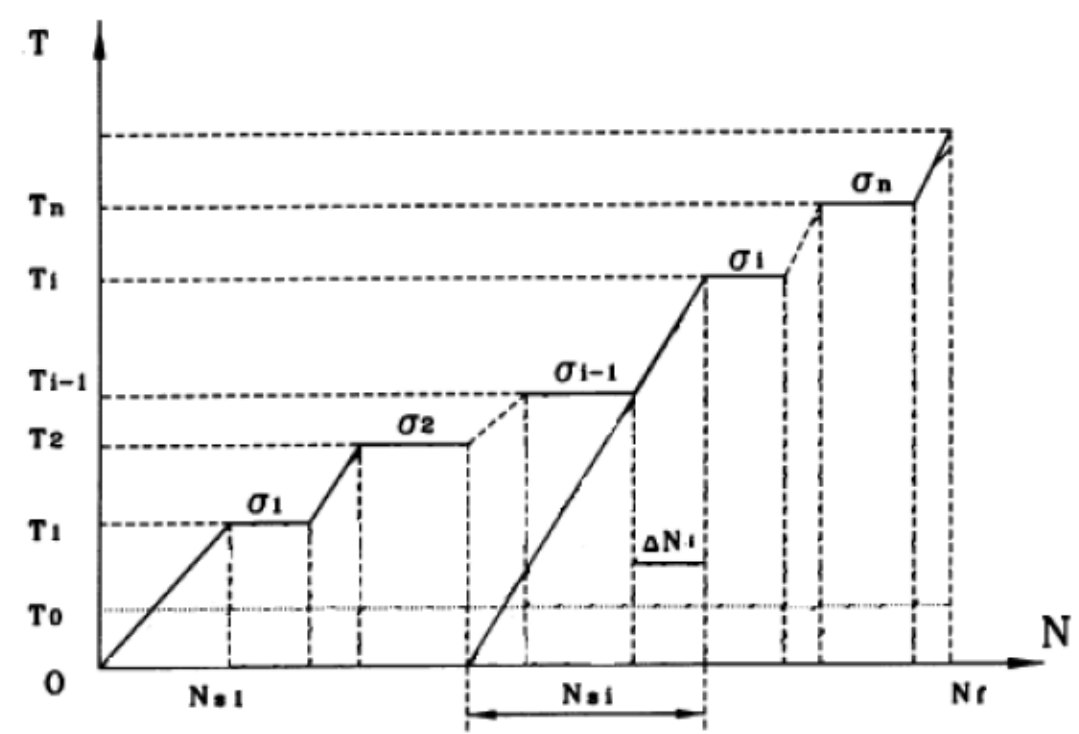

Figura 3.7: Procedimento para carregamento com diferentes patamares do espécime para determinação da curva de fadiga do material.

O $N_{s i}$ pode ser determinado segundo a Equação 3.16:

$$
N_{s i}=\frac{\Delta N_{i} T_{i}}{T_{i}-T_{i-1}}
$$

onde $\Delta N_{i}$ é o número de ciclos do começo da aplicação do carregamento até a estabilização e $T_{i}$ é a temperatura de estabilização para nível de temperatura.

$N_{f}$ pode ser determinado substituindo os valores da temperatura de estabilização e dos ciclos para estabilização na Equação 3.15. 


\section{Procedimento Experimental}

\subsection{Pré-Experimental}

Antes de começar o experimento alguns preparos foram feitos, para assim melhores resultados serem alcançados e uma confiabilidade maior. Neste capítulo será explicado cada passo desses preparos, tais como, tipo de espécime, material do espécime, dimensões, preparação, máquina de aplicação de carga e procedimentos experimentais gerais e precauções.

\subsubsection{Material}

O material escolhido para ser estudado nesse trabalho foi o policarbonato, pois possui alta emissividade infravermelha, o que o torna uma boa opção para o trabalho com termografia.

São empregados na indústria e também em construções onde são utilizados em telhados e paredes de áreas externas como jardins de inverno, garagens, estufas e piscinas, onde há a necessidade da passagem de luz natural. Na tabela 4.1 são apresentados os dados do policarbonato utilizado, [5].

Tabela 4.1: Propriedades policarbonato

\begin{tabular}{|c|c|c|}
\hline Propriedade & Valor & Unidade \\
\hline Densidade & 1150 & $\frac{\mathrm{kg}}{\mathrm{m}^{3}}$ \\
\hline Modulo de Young & 2300 & $\mathrm{MPa}$ \\
\hline Coeficiente de Poisson & 0.39 & - \\
\hline Limite de escoamento & 65 & $\mathrm{MPa}$ \\
\hline Tensão Nominal de Ruptura a Tração & 60 & $\mathrm{MPa}$ \\
\hline Tenacidade à Fratura & 3 & $\mathrm{MPa} \sqrt{\mathrm{m}}$ \\
\hline Temperatura de Transição Vítrea & 420 & $\mathrm{~K}$ \\
\hline Temperatura de Fusão & 573 & $\mathrm{~K}$ \\
\hline Emissividade Infravermelha & 0.9 & - \\
\hline Condutividade Térmica & 0.22 & $\mathrm{~W} / \mathrm{mK}$ \\
\hline
\end{tabular}


Na Figura 4.1 são apresentados duas curvas Tensão vs Deformação do policarbonato para dois tipos de CPs diferentes para aquisição das propriedades mecânicas reais do material, [5].
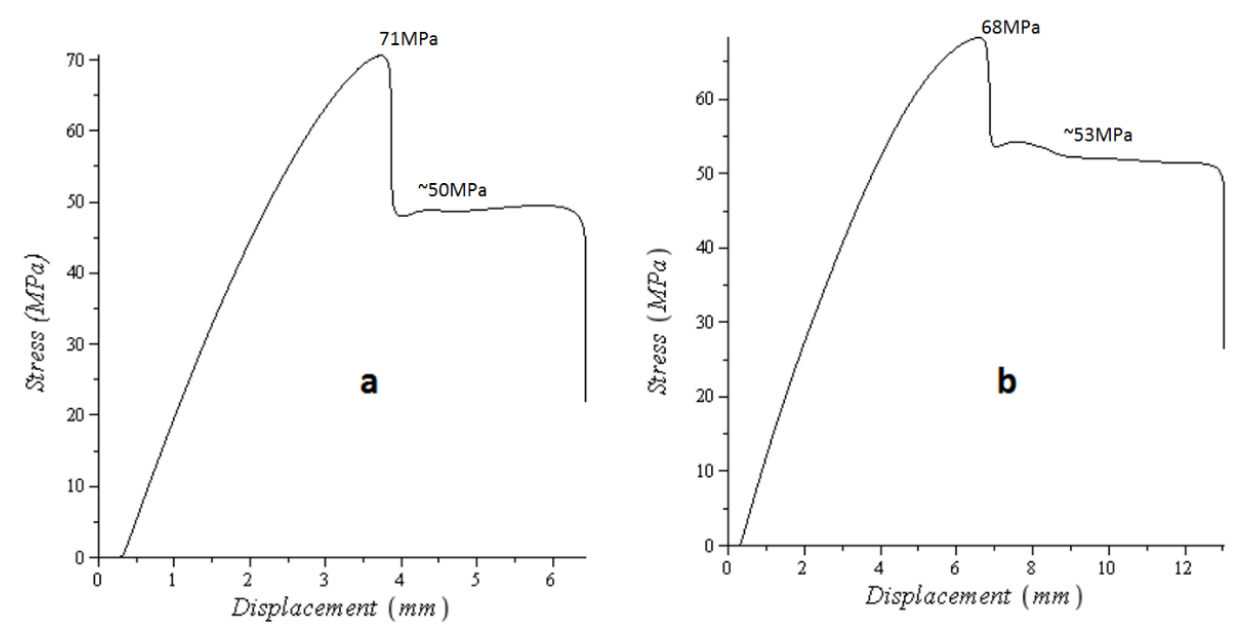

Figura 4.1: Gráfico tensão vs deformação: a) CP de tração CR;

b) Espécime de tração com lados paralelos [5].

\subsubsection{Corpo de Prova}

A escolha do corpo de prova foi baseada em características físicas que possibilitam e facilitam o estudo do mesmo. Usa um corpo de prova de tração em que a seção intermediária é usinada com um raio constante de $11 \mathrm{~cm}$, de modo que a seção transversal do meio seja o ponto crítico da peça. A Figura 4.2 mostra como é o corpo de prova e suas dimensões e tabela mostra as dimensões importantes de cada corpo de prova usado.

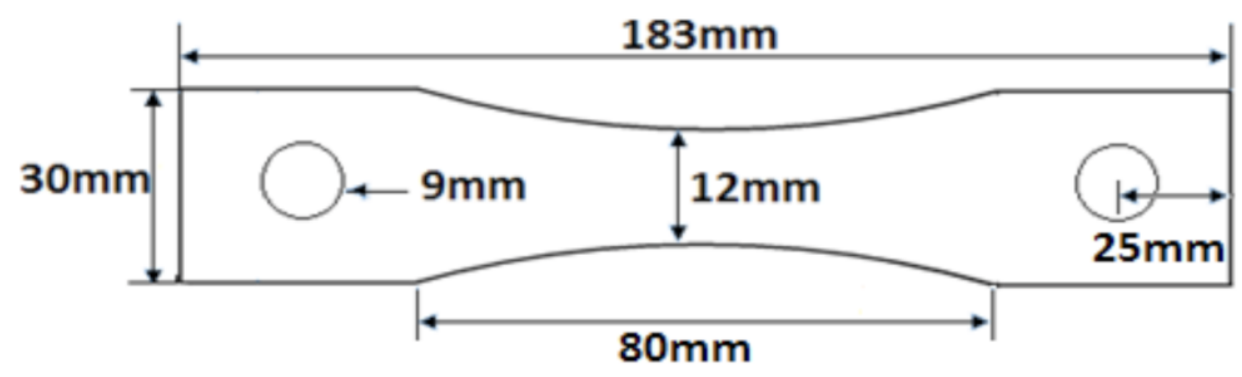

Figura 4.2: Corpo de Prova com suas dimensões [5]. 
Tabela 4.2: Dimensões dos CP utilizados nos ensaios.

\begin{tabular}{|c|c|c|c|}
\hline $\mathbf{C P}$ & Espessura (mm) & Largura (mm) & Área $\left.\mathbf{( m m}^{\mathbf{2}}\right)$ \\
\hline 1 & 3.92 & 11.60 & 45.47 \\
\hline 2 & 3.93 & 11.60 & 45.59 \\
\hline 3 & 3.92 & 11.50 & 45.08 \\
\hline 4 & 3.935 & 11.70 & 46.04 \\
\hline 5 & 3.94 & 11.70 & 46.10 \\
\hline 6 & 3.90 & 11.70 & 45.63 \\
\hline 7 & 3.935 & 11.60 & 45.646 \\
\hline 10 & 3.93 & 11.80 & 46.375 \\
\hline 12 & 3.94 & 11.75 & 46.295 \\
\hline 13 & 3.935 & 12.00 & 47.22 \\
\hline
\end{tabular}

Por causa dos furos feitos para encaixar o corpo de prova na máquina, a seção transversal média deixou de ser o ponto crítico da peça. Esta passou a ser a seção dos furos de carregamento e, portanto, poderia ocorrer fissura ali. Para resolver esse problema usou-se uma garra desenvolvida especificamente para esse corpo de prova. Essa garra possibilita a transmissão de carga para a amostra por fricção e, consequentemente, evitar a concentração de tensão no furo. A Figura 4.3 mostra uma foto de uma amostra montada com as garras.

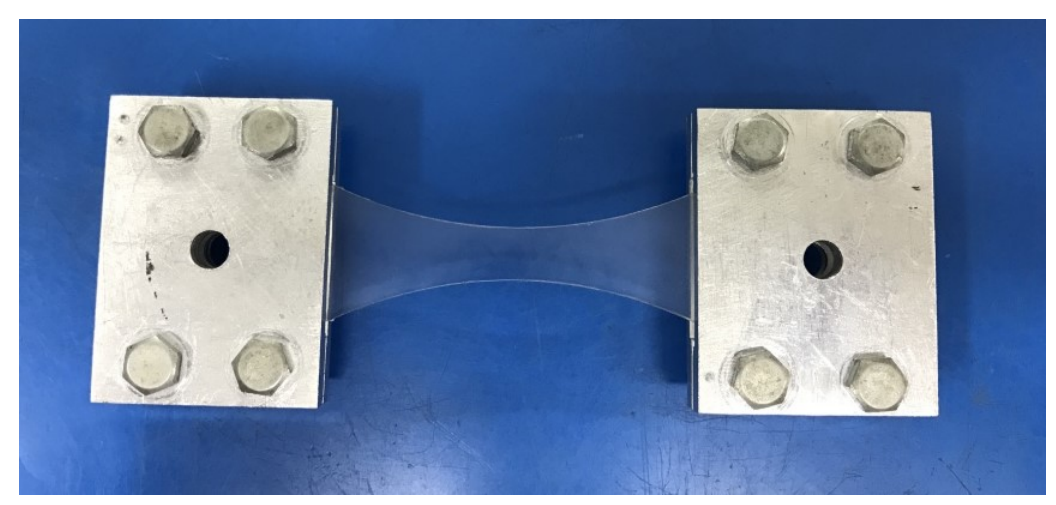

Figura 4.3: CP com garras montadas. 


\subsubsection{Tratamento Térmico}

Através da utilização da fotoelasticidade e de um polariscópio foram observadas tensões residuais presente nos corpos de prova, que são devidas aos processos de fabricação, tanto da chapa de policarbonato quanto da retirada e usinagem do espécime. Para que os resultados dos ensaios não fossem afetados pelas tensões residuais, foi realizado um tratamento térmico de recozimento, com o objetivo de eliminar essas tensões presentes na ausência de esforços. A Figura 4.4 mostra a diferença nos padrões de franjas isocromáticas do espécime antes e depois do tratamento térmico.

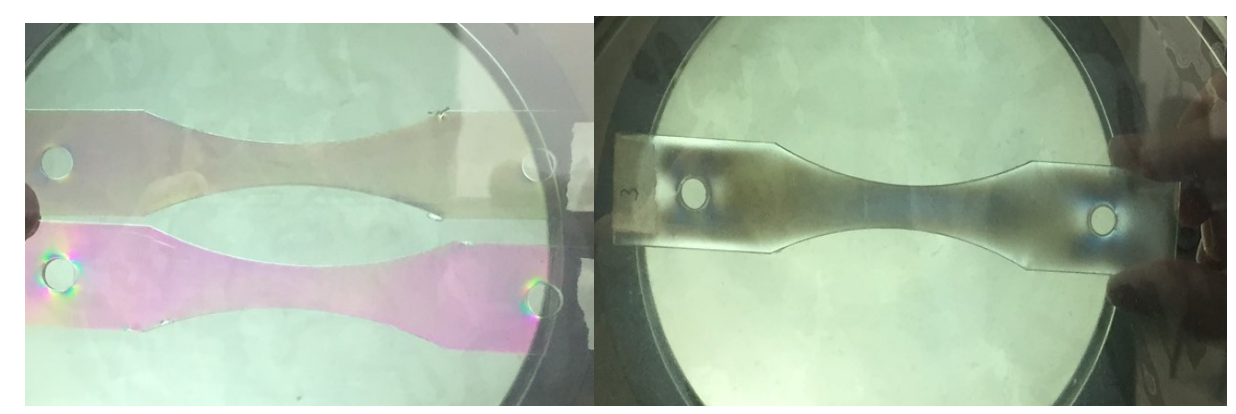

Figura 4.4: Foto corpo de prova antes e depois do recozimento visto através de polarioscopio.

O processo de recozimento foi feito no forno Photolastic Inc, em um processo que tem duração de aproximadamente 10 horas. Foram realizados diversos testes até conseguir-se alcançar o resultado esperado e após o primeiro recozimento bem sucedido o processo foi feito usando dois corpos de prova por vez, acelerando o processo. $\mathrm{Na}$ Figura 4.5 vê-se como o corpo de prova foi colocado dentro do forno. O corpo de prova foi colocado coberto por talco entre duas chapas de vidro também cobertas por talco. $\mathrm{O}$ talco tem o objetivo de diminuir o atrito com o vidro e o vidro tem como objetivo fazer peso sobre o corpo de prova e consequentemente não deixar que o mesmo se deforme. 


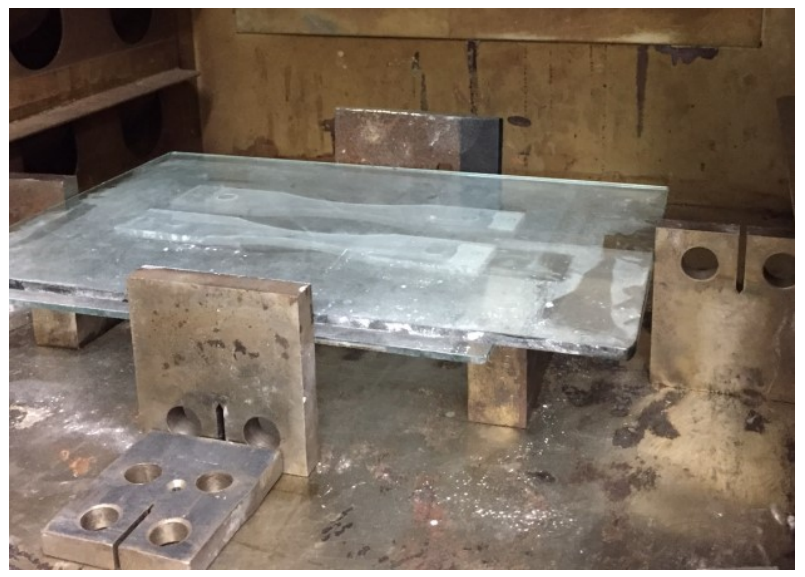

Figura 4.5: Corpos de prova preparados e posicionados dentro do forno para o processo de recozimento.

O tratamento térmico dos espécimes segue o seguinte procedimento: aquecimento estabilizando na temperatura máxima e resfriando. $\mathrm{O}$ aquecimento foi feito até uma temperatura aproximada de $177^{\circ} \mathrm{C}$ em um intervalo de aproximadamente 3 horas, ficando nessa temperatura por aproximadamente 4 horas. Após as 7 horas, o forno volta a reduzir a temperatura até a temperatura ambiente, num processo de aproximadamente 3 horas.

Na Figura 4.6 vê-se a foto do came que é um elemento mecânico responsável por transmitir movimento para o ponteiro de temperatura do forno através de sua rotação.

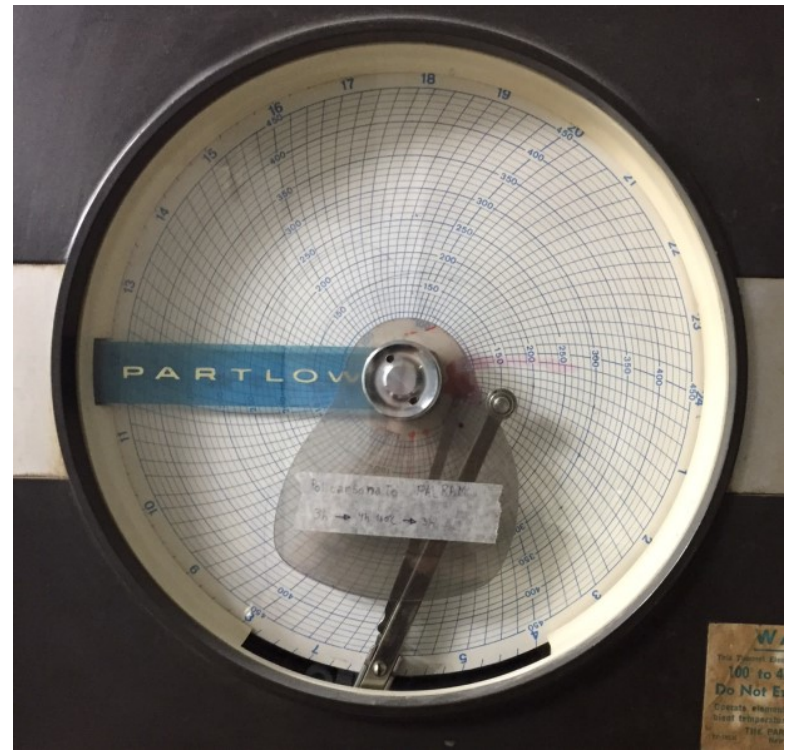

Figura 4.6: Quadro do forno com came e ponteiro. 
$\mathrm{Na}$ Figura 4.7 a seguir tem-se o processo de recozimento quase no seu final. Nele é possível ver uma linha em vermelho que representa o "caminho" percorrido pelo ponteiro de temperatura e vê-se que forno atinge a temperatura máxima de aproximadamente $350{ }^{\circ} \mathrm{F}$ que equivale a $177^{\circ} \mathrm{C}$

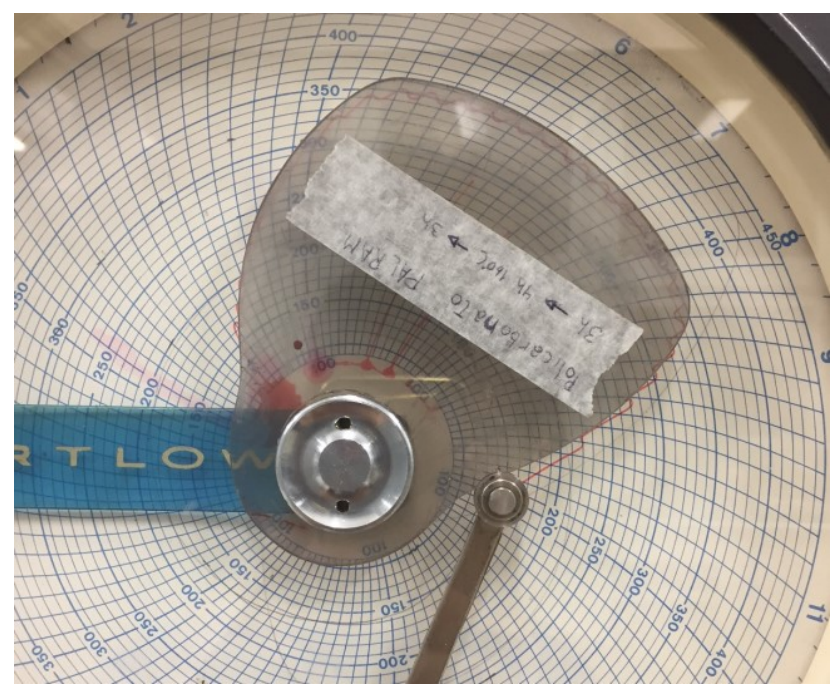

Figura 4.7: Quadro com cames e "caminho" percorrido pelo ponteiro de temperatura.

\subsubsection{Isolamento Térmico}

Como o experimento baseia-se em resultados obtidos através de uma câmera térmica, é de extrema importância a anulação ou diminuição de qualquer interferência externa que possa ser captada pela câmera, como a radiação proveniente de outros corpos, por exemplo pessoas, luz e equipamentos, entre outros. Para diminuir essas interferências foi desenvolvida uma caixa em que os testes de fadiga possam ser realizados dentro da mesma. Além disso sacos plásticos foram usados para fechas as aberturas da porta e um furo foi feito para encaixe da câmera. 


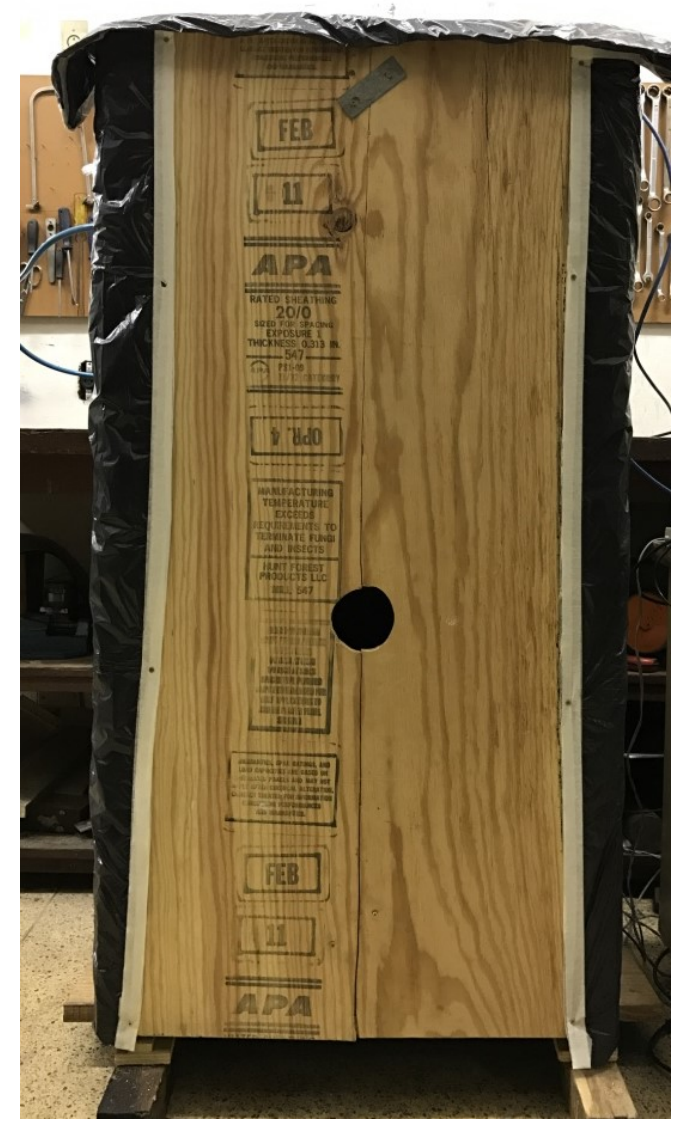

Figura 4.8: Caixa de madeira para isolamento

$\mathrm{Na}$ figura 4.8 é possível ver exatamente como ficou a caixa para isolamento e pela Figura 4.9 pode-se ver a diferença real de um ensaio feito fora do isolamento térmico [5] e um ensaio feito dentro do isolamento, e é possível ver a grande melhora que ela traz para o experimento.
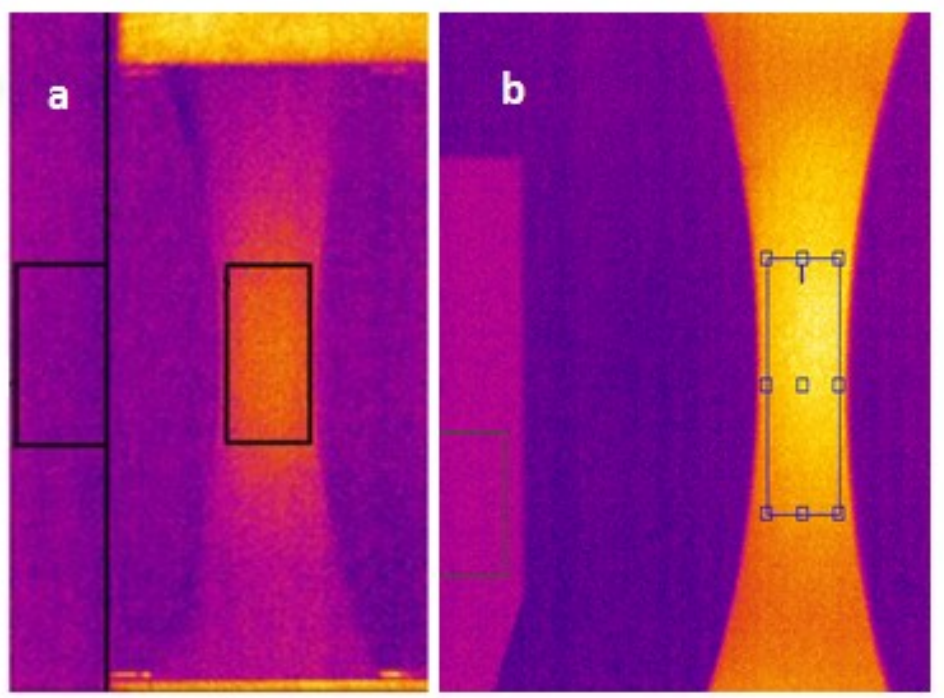

Figura 4.9: Imagem do espécime visto a partir da câmera térmica; a) Sem isolamento térmico [5];

b) Com isolamento térmico. 


\subsection{Equipamentos Utilizados nos Ensaios}

\subsubsection{Câmera Infravermelha}

A câmera usada em todo o trabalho é uma FLIR A655sc. Ela usa uma matriz de plano focal (FPA) de 640 por 480 pixel de 17 microns cada, a frequência de aquisição de dados é de 50 até $200 \mathrm{~Hz}$ e a faixa espectral é de 7.5 à $14 \mu \mathrm{m}$ [13].

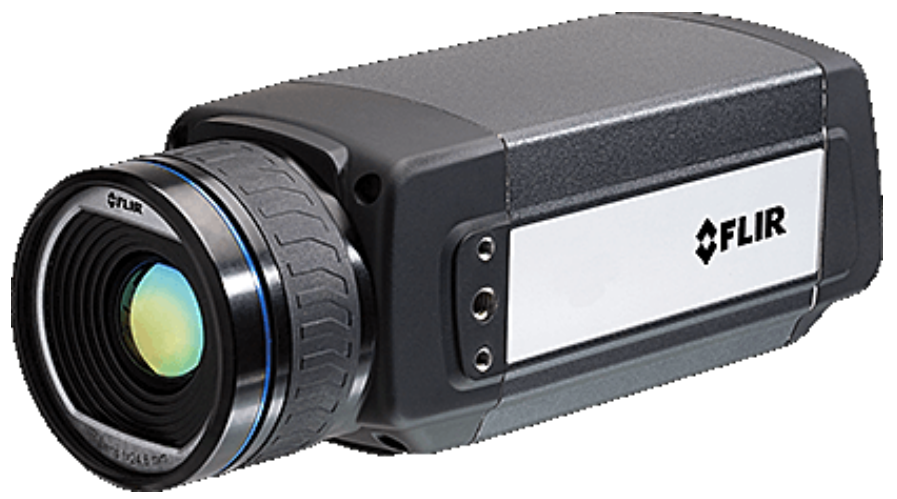

Figura 4.10: Câmera Flir A655sc, [19]

\subsubsection{Máquina para Aplicação de Carregamento Cíclico}

Para fazer o estudo foi utilizada uma máquina de ensaios pneumática, com seu desenvolvimento mostrado em [20]. A máquina é equipada com um servo válvula que é controlado manualmente e através de um programa de computador. A carga foi controlada através de três válvulas que regulam a pressão do ar que entra no musculo pneumático. Uma célula de carga, conectada em serie com o espécime, é responsabel por receber os dados e passar para o programa. A Figura 4.11 mostra uma foto da máquina com seus componentes e com o espécime em sua posição de teste e a Figura 4.12 mostra a captura de tela do software de controle da aplicação do carregamento que era controlada através de uma válvula. 


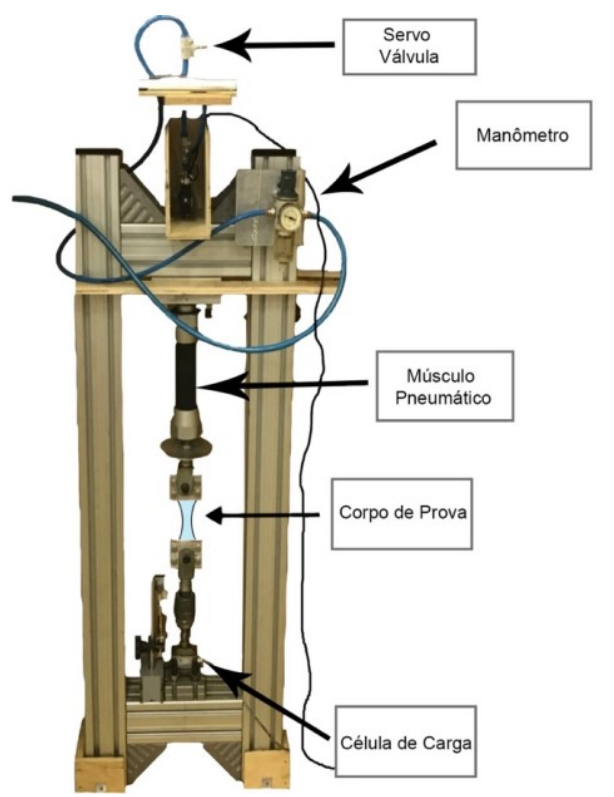

Figura 4.11: Máquina pneumática usada no meu experimento

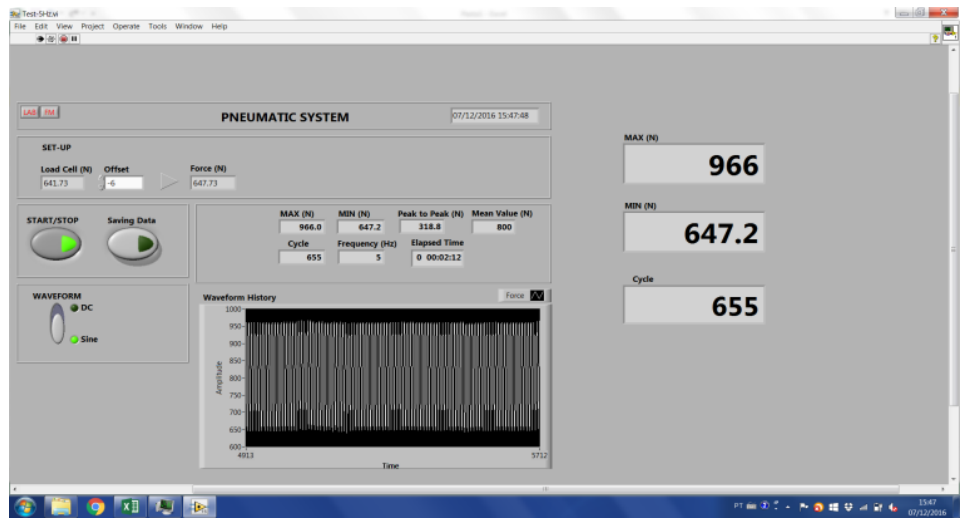

Figura 4.12: Tela do software de controle da máquina

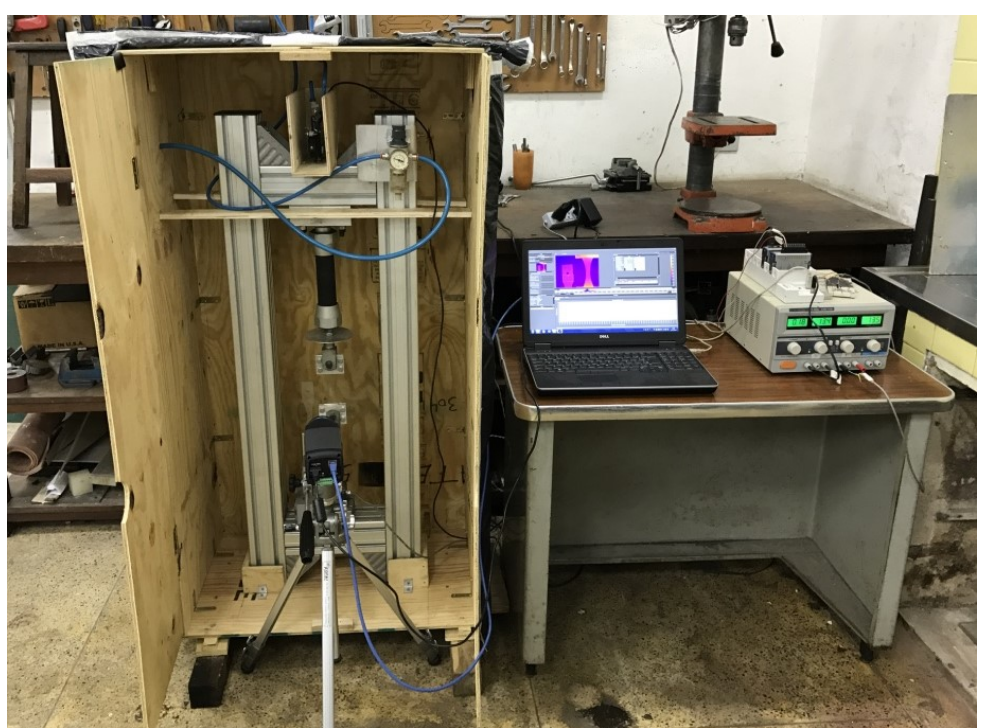

Figura 4.13: Foto com todo o experimento montado com o isolamento térmico aberto para visualização da máquina. 


\section{Resultados e Discussões}

\subsection{Medição do Limite de Fadiga Utilizando a Termografia}

Foram utilizados 4 CPs diferentes para medição do limite de fadiga utilizando o método de Risitano, apresentado no item 3.5.1, procurando reproduzir os experimentos realizados por [5]. Foram aplicados diferentes patamares de tensão, diferentes tensões alternadas e médias, que possibilitam o cálculo de tensões equivalentes de Goodman, medindo as temperaturas e registrando os ciclos durante a estabilização.

A seguir são apresentados os patamares de tensão utilizados em cada teste e as temperaturas de estabilização para cada patamar.

\begin{tabular}{|c|c|c|c|c|c|c|c|c|c|c|c|}
\hline \multicolumn{12}{|c|}{ CP1 } \\
\hline $\begin{array}{c}\text { Patamar } \\
\text { de } \\
\text { tensão }\end{array}$ & $\begin{array}{c}\text { Área } \\
\left(\mathbf{m m}^{2}\right)\end{array}$ & $\begin{array}{c}F_{\max } \\
(\mathbf{N})\end{array}$ & $\begin{array}{c}F_{\min } \\
(\mathbf{N})\end{array}$ & $\begin{array}{c}\sigma_{\max } \\
(\mathrm{MPa})\end{array}$ & $\begin{array}{c}\sigma_{\min } \\
(\mathrm{MPa})\end{array}$ & $\begin{array}{c}\sigma_{a} \\
(\mathbf{M P a})\end{array}$ & $\begin{array}{c}\sigma_{m} \\
(\mathbf{M P a})\end{array}$ & $\begin{array}{c}\sigma_{e q} \\
(\mathrm{MPa})\end{array}$ & $\left(\begin{array}{c}\mathbf{R} \\
\left(\frac{\sigma_{\max }}{\sigma_{\min }}\right)\end{array}\right.$ & $\begin{array}{c}T_{\text {estab }} \\
\left({ }^{\circ} \mathrm{C}\right)\end{array}$ & $\begin{array}{l}N_{\text {estab }} \\
\text { (ciclos) }\end{array}$ \\
\hline 1 & 45.47 & 546.00 & 175.00 & 12.01 & 3.85 & 4.08 & 7.93 & 4.61 & 0.32 & 0.59 & 2526 \\
\hline 2 & 45.47 & 681.00 & 232.00 & 14.98 & 5.10 & 4.94 & 10.04 & 5.78 & 0.34 & 0.72 & 7430 \\
\hline 3 & 45.47 & 832.50 & 310.60 & 18.31 & 6.83 & 5.74 & 12.57 & 7.02 & 0.37 & 0.76 & 12289 \\
\hline 4 & 45.47 & 1152.30 & 527.10 & 25.34 & 11.59 & 6.87 & 18.47 & 9.39 & 0.46 & 0.86 & 17156 \\
\hline 5 & 45.47 & 1355.90 & 629.20 & 29.82 & 13.84 & 7.99 & 21.83 & 11.69 & 0.46 & 0.92 & 21956 \\
\hline 6 & 45.47 & 1574.30 & 814.40 & 34.62 & 17.91 & 8.36 & 26.27 & 13.49 & 0.52 & 1.02 & 26822 \\
\hline 7 & 45.47 & 1715.40 & 906.00 & 37.72 & 19.92 & 8.90 & 28.82 & 15.29 & 0.53 & 1.13 & 31948 \\
\hline
\end{tabular}

\begin{tabular}{|c|c|c|c|c|c|c|c|c|c|c|c|}
\hline \multicolumn{10}{|c|}{$\mathbf{C P 2}$} \\
\hline $\begin{array}{c}\text { Patamar } \\
\text { de } \\
\text { tensão }\end{array}$ & $\begin{array}{c}\text { Área } \\
\left(\mathbf{m m}^{2}\right)\end{array}$ & $\begin{array}{c}\boldsymbol{F}_{\max } \\
(\mathbf{N})\end{array}$ & $\begin{array}{c}\boldsymbol{F}_{\min } \\
(\mathbf{N})\end{array}$ & $\begin{array}{c}\boldsymbol{\sigma}_{\max } \\
(\mathbf{M P a})\end{array}$ & $\begin{array}{c}\boldsymbol{\sigma}_{\min } \\
(\mathbf{M P a})\end{array}$ & $\begin{array}{c}\boldsymbol{\sigma}_{\boldsymbol{a}} \\
(\mathbf{M P a})\end{array}$ & $\begin{array}{c}\boldsymbol{\sigma}_{\boldsymbol{m}} \\
(\mathbf{M P a})\end{array}$ & $\begin{array}{c}\boldsymbol{\sigma}_{\text {eq }} \\
(\mathbf{M P a})\end{array}$ & $\begin{array}{c}\mathbf{R} \\
\left(\frac{\boldsymbol{\sigma}_{\text {max }}}{\boldsymbol{\sigma}_{\min }}\right)\end{array}$ & $\begin{array}{c}\boldsymbol{T}_{\text {estab }} \\
\left({ }^{\circ} \mathbf{C}\right)\end{array}$ & $\begin{array}{c}\boldsymbol{N}_{\text {estab }} \\
(\mathbf{c i c l o s})\end{array}$ \\
\hline 1 & 45.59 & 540.20 & 167.50 & 11.85 & 3.67 & 4.09 & 7.76 & 4.61 & 0.31 & 0.70 & 2886 \\
\hline 2 & 45.59 & 672.10 & 240.50 & 14.74 & 5.28 & 4.73 & 10.01 & 5.54 & 0.36 & 0.81 & 7561 \\
\hline 3 & 45.59 & 842.70 & 320.00 & 18.49 & 7.02 & 5.73 & 12.75 & 7.03 & 0.38 & 0.83 & 12764 \\
\hline 4 & 45.59 & 1148.10 & 488.60 & 25.18 & 10.72 & 7.23 & 17.95 & 9.78 & 0.43 & 0.90 & 17520 \\
\hline 5 & 45.59 & 1328.50 & 632.10 & 29.14 & 13.87 & 7.64 & 21.50 & 11.10 & 0.48 & 0.96 & 22724 \\
\hline 6 & 45.59 & 1593.90 & 777.00 & 34.96 & 17.04 & 8.96 & 26.00 & 14.38 & 0.49 & 1.18 & 27683 \\
\hline 7 & 45.59 & 1706.00 & 856.00 & 37.42 & 18.78 & 9.32 & 28.10 & 15.73 & 0.50 & 1.45 & 33130 \\
\hline 8 & 45.59 & 1763.00 & 895.00 & 38.67 & 19.63 & 9.52 & 29.15 & 16.48 & 0.51 & 1.54 & 36545 \\
\hline
\end{tabular}




\begin{tabular}{|c|c|c|c|c|c|c|c|c|c|c|c|}
\hline \multicolumn{12}{|c|}{ CP3 } \\
\hline $\begin{array}{c}\text { Patamar } \\
\text { de } \\
\text { tensão }\end{array}$ & $\begin{array}{c}\text { Área } \\
\left(\mathrm{mm}^{2}\right)\end{array}$ & $\begin{array}{c}F_{\max } \\
(\mathbf{N})\end{array}$ & $\begin{array}{c}F_{\min } \\
(\mathbf{N})\end{array}$ & $\begin{array}{c}\sigma_{\max } \\
(\mathrm{MPa})\end{array}$ & $\begin{array}{c}\sigma_{\min } \\
(\mathrm{MPa})\end{array}$ & $\begin{array}{c}\sigma_{a} \\
(\mathbf{M P a})\end{array}$ & $\begin{array}{c}\sigma_{m} \\
(\mathbf{M P a})\end{array}$ & $\begin{array}{c}\sigma_{e q} \\
(\mathrm{MPa})\end{array}$ & $\left(\begin{array}{c}\mathbf{R} \\
\left(\frac{\sigma_{\max }}{\sigma_{\min }}\right)\end{array}\right.$ & $\begin{array}{c}T_{\text {estab }} \\
\left({ }^{\circ} \mathrm{C}\right)\end{array}$ & $\begin{array}{l}N_{\text {estab }} \\
\text { (ciclos) }\end{array}$ \\
\hline 1 & 45.08 & 540.70 & 199.00 & 11.99 & 4.41 & 3.79 & 8.20 & 4.30 & 0.37 & 0.70 & 1537 \\
\hline 2 & 45.08 & 672.00 & 248.00 & 14.91 & 5.50 & 4.70 & 10.20 & 5.52 & 0.37 & 0.71 & 3621 \\
\hline 3 & 45.08 & 829.00 & 321.00 & 18.39 & 7.12 & 5.63 & 12.76 & 6.91 & 0.39 & 0.81 & 5507 \\
\hline 4 & 45.08 & 1162.00 & 529.00 & 25.78 & 11.73 & 7.02 & 18.76 & 9.64 & 0.46 & 0.87 & 7734 \\
\hline 5 & 45.08 & 1330.00 & 633.00 & 29.50 & 14.04 & 7.73 & 21.77 & 11.29 & 0.48 & 0.93 & 9279 \\
\hline 6 & 45.08 & 1565.00 & 800.00 & 34.72 & 17.75 & 8.48 & 26.23 & 13.69 & 0.51 & 1.04 & 11513 \\
\hline 7 & 45.08 & 1715.60 & 899.20 & 38.06 & 19.95 & 9.06 & 29.00 & 15.62 & 0.52 & 1.08 & 13542 \\
\hline 8 & 45.08 & 1771.00 & 954.00 & 39.29 & 21.16 & 9.06 & 30.22 & 16.12 & 0.54 & 1.20 & 15792 \\
\hline 9 & 45.08 & 1896.00 & 1024.00 & 42.06 & 22.72 & 9.67 & 32.39 & 18.23 & 0.54 & 1.19 & 17615 \\
\hline 10 & 45.08 & 2033.00 & 1115.00 & 45.10 & 24.73 & 10.18 & 34.92 & 20.61 & 0.55 & 1.30 & 19731 \\
\hline 11 & 45.08 & 2192.00 & 1215.00 & 48.62 & 26.95 & 10.84 & 37.79 & 23.96 & 0.55 & 1.46 & 21815 \\
\hline 12 & 45.08 & 2311.00 & 1361.00 & 51.26 & 30.19 & 10.54 & 40.73 & 25.72 & 0.59 & 1.57 & 22734 \\
\hline
\end{tabular}

\begin{tabular}{|c|c|c|c|c|c|c|c|c|c|c|c|}
\hline \multicolumn{12}{|c|}{ CP5 } \\
\hline $\begin{array}{c}\text { Patamar } \\
\text { de } \\
\text { tensão }\end{array}$ & $\begin{array}{c}\text { Área } \\
\left(\mathbf{m m}^{2}\right)\end{array}$ & $\begin{array}{c}F_{\max } \\
(\mathbf{N})\end{array}$ & $\begin{array}{c}F_{\min } \\
(\mathbf{N})\end{array}$ & $\begin{array}{c}\sigma_{\max } \\
(\mathrm{MPa})\end{array}$ & $\begin{array}{c}\sigma_{\min } \\
(\mathbf{M P a})\end{array}$ & $\begin{array}{c}\sigma_{a} \\
(\mathbf{M P a})\end{array}$ & $\begin{array}{c}\sigma_{m} \\
(\mathbf{M P a})\end{array}$ & $\begin{array}{c}\sigma_{e q} \\
(\mathrm{MPa})\end{array}$ & $\left(\begin{array}{c}\mathbf{R} \\
\left(\frac{\sigma_{\max }}{\sigma_{\min }}\right)\end{array}\right.$ & $\begin{array}{c}T_{\text {estab }} \\
\left({ }^{\circ} \mathbf{C}\right)\end{array}$ & $\begin{array}{l}N_{\text {estab }} \\
\text { (ciclos) }\end{array}$ \\
\hline 1 & 46.10 & 571.10 & 174.20 & 12.39 & 3.78 & 4.30 & 8.08 & 4.88 & 0.31 & 0.68 & 3375 \\
\hline 2 & 46.10 & 687.60 & 238.20 & 14.92 & 5.17 & 4.87 & 10.04 & 5.70 & 0.35 & 0.82 & 7759 \\
\hline 3 & 46.10 & 834.50 & 323.30 & 18.10 & 7.01 & 5.54 & 12.56 & 6.78 & 0.39 & 0.92 & 12283 \\
\hline 4 & 46.10 & 1168.40 & 520.20 & 25.35 & 11.28 & 7.03 & 18.32 & 9.57 & 0.45 & 1.03 & 16933 \\
\hline 5 & 46.10 & 1339.20 & 639.70 & 29.05 & 13.88 & 7.59 & 21.46 & 11.01 & 0.48 & 1.05 & 21036 \\
\hline 6 & 46.10 & 1577.40 & 784.10 & 34.22 & 17.01 & 8.60 & 25.61 & 13.68 & 0.50 & 1.21 & 25742 \\
\hline 7 & 46.10 & 1724.10 & 906.20 & 37.40 & 19.66 & 8.87 & 28.53 & 15.13 & 0.53 & 1.35 & 30700 \\
\hline
\end{tabular}

A seguir são apresentados os gráficos da variação de temperatura entre o CP e a temperatura de referência $(\Delta T)$, e o número de ciclos de cada experimento. Cada conjunto de linhas, horizontal e vertical, representam um ponto onde $\Delta T$ estabilizou, segundo um critério arbitrário, visual, de análise do gráfico. 
CP 1

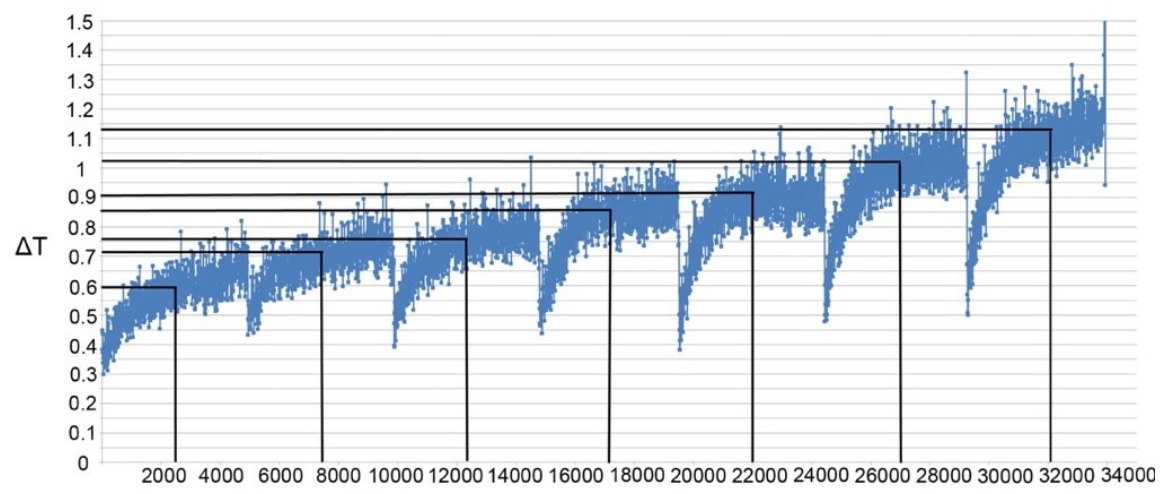

Ciclos

CP 2

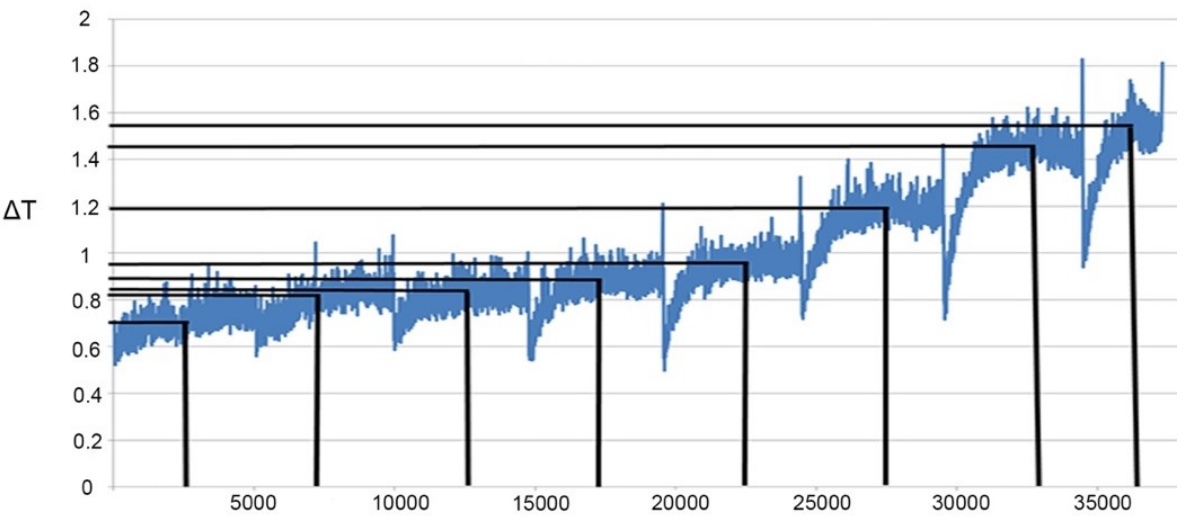

Ciclos

CP 3

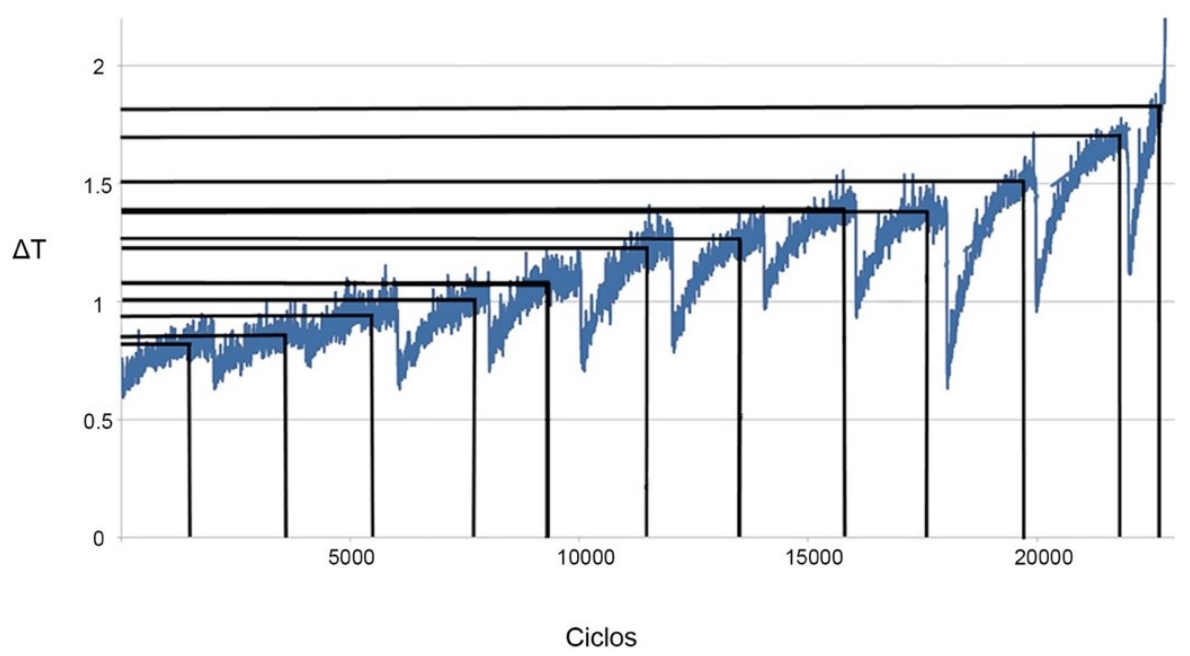


CP 5

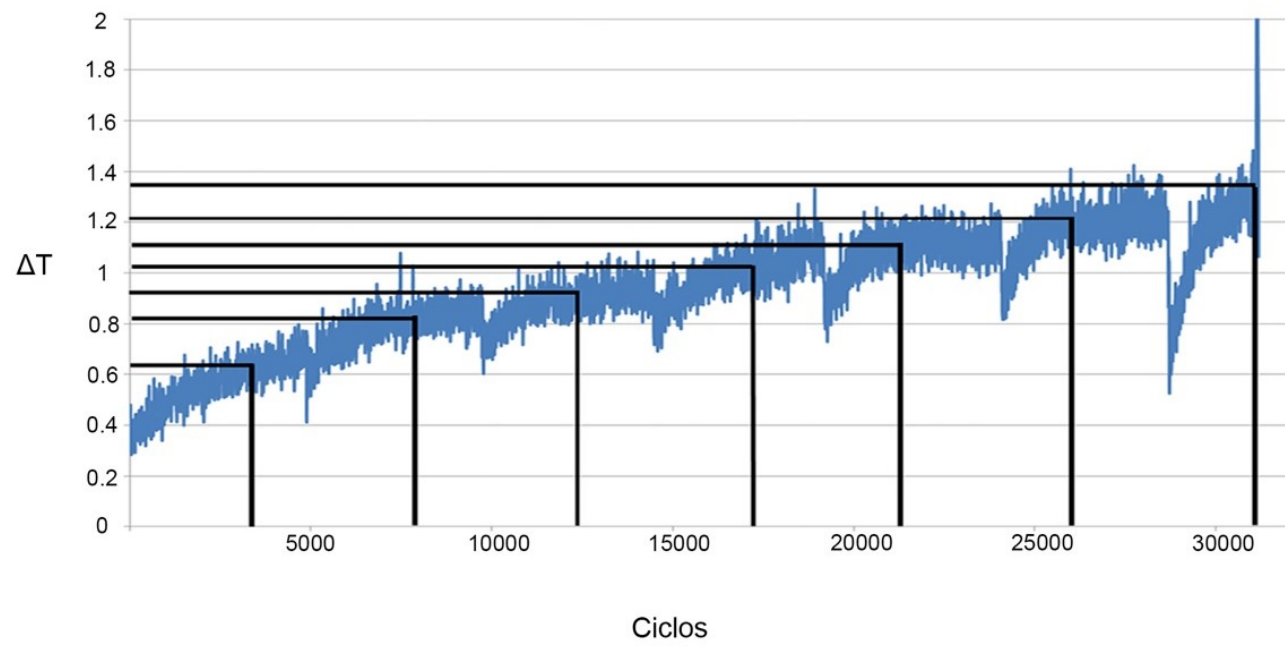

Aplicando o método de Risitano para obtenção do limite de fadiga tem-se:

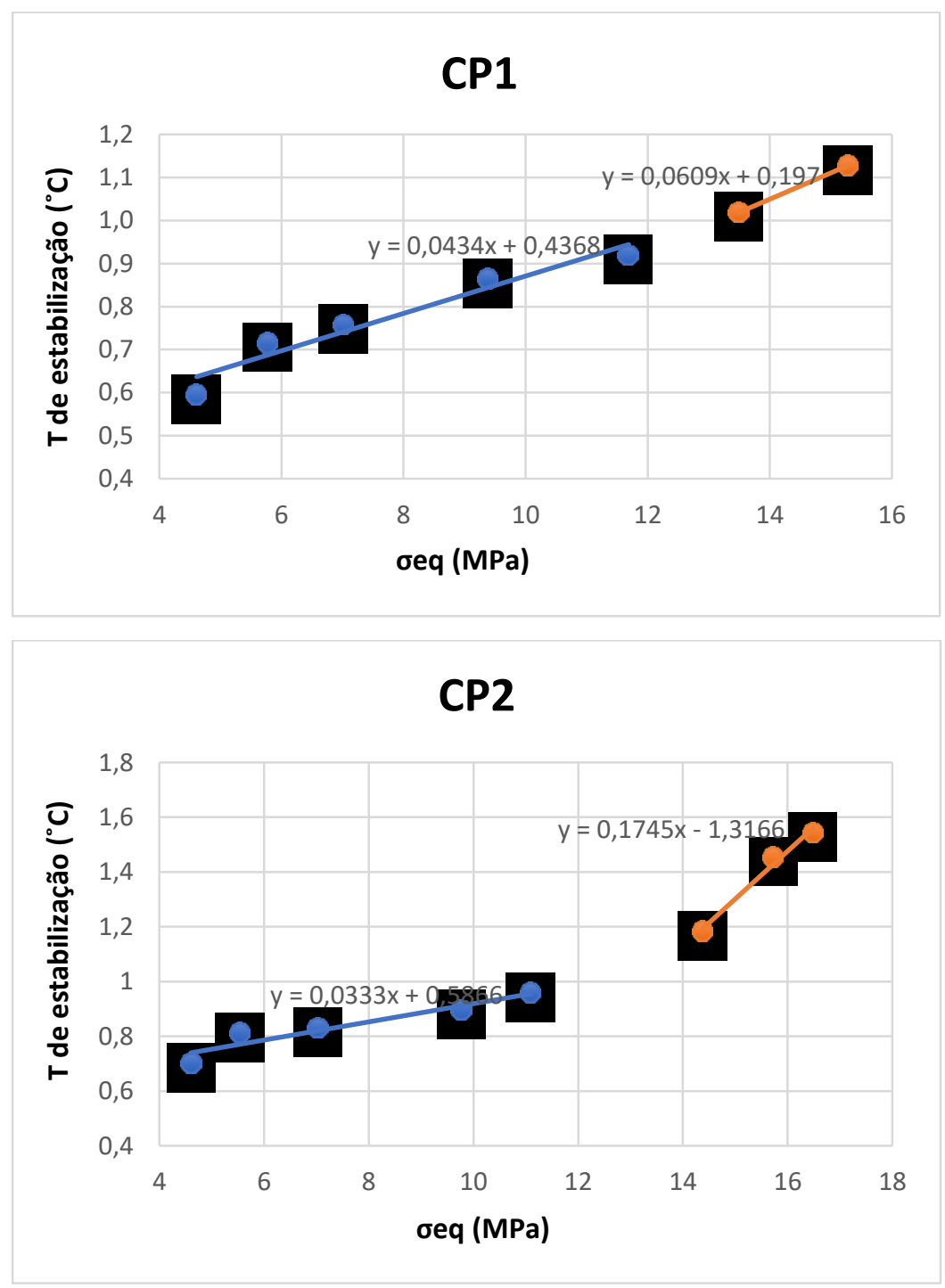




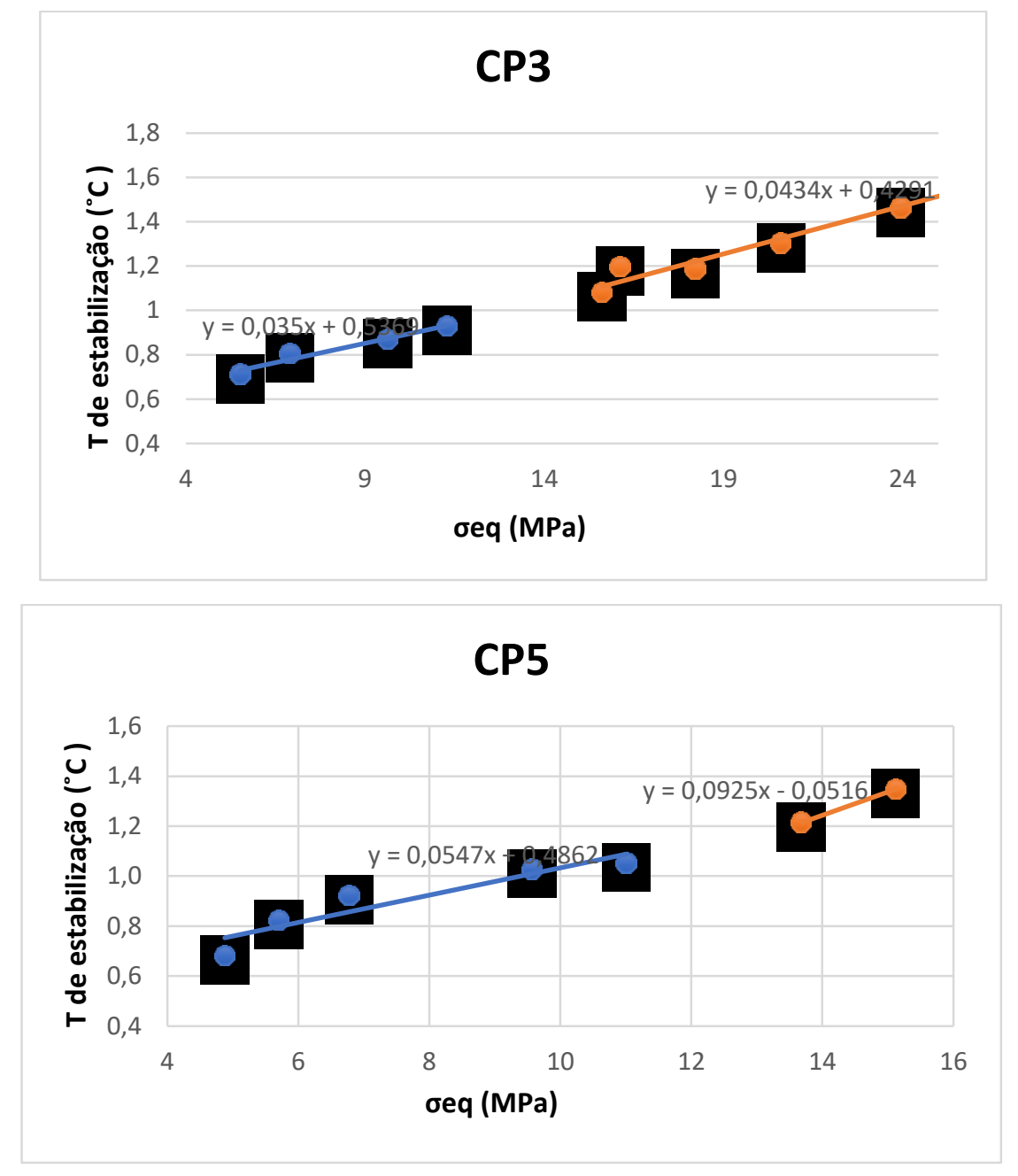

A média do limite de fadiga medido nos 4 testes foi de $13.56 \mathrm{MPa}$, vide Tabela 5.1, este valor foi bem similar ao medido na referência [5] e esta dentro do erro de $\pm 15 \%$ reportado na aplicação do método. Apesar dos resultados medidos estarem dentro do valor esperado, é possível perceber que em alguns testes a reta ajustada para níveis de tensão abaixo do limite de fadiga e a reta ajustada para tensões acima do limite de fadiga apresentam inclinação similar, o que não é desejável, pois para tensões acima do limite de fadiga a inclinação da reta ajustada deverá ser mais acentuada, como no caso do CP2. Não foi possível determinar a causa para isso, entretanto atribui-se esse fenômeno a análise dos dados experimentais, dificultando assim a determinação da temperatura estabilizada.

Foi reportado na literatura que o limite de fadiga pode variar no intervalo de $6 \mathrm{MPa}$ até $13 \mathrm{MPa}[21]$. 
Tabela 5.1: Limite de fadiga medido em cada CP.

\begin{tabular}{|c|c|}
\hline $\mathbf{C P}$ & $\boldsymbol{S}_{\boldsymbol{L}}(\mathbf{M P a})$ \\
\hline 1 & 13.70 \\
\hline 2 & 13.48 \\
\hline 3 & 12.83 \\
\hline 5 & 14.23 \\
\hline Média & 13.56 \\
\hline
\end{tabular}

\subsection{Experimento de Medição da Curva SN Utilizando a Termografia}

Implementando a metodologia descrita no item 3.5.2, através da aplicação da equação 3.15 , com um de $\phi$ igual a $28905{ }^{\circ} \mathrm{C}$ ciclo, e da equação 3.16 , determinou-se a curva SN do material utilizando um espécime, submetido a diferentes patamares de tensão, todos superiores ao limite de fadiga medido nos experimentos anteriores.

Foram realizados 3 teste similares com esse mesmo CP. Foram também utilizados os resultados dos ensaios para a determinação do limite de fadiga, no entanto apenas os pontos que apresentaram um tensão equivalente superior ao limite de fadiga calculado foram levados em consideração.

\begin{tabular}{|c|c|c|c|c|c|c|c|c|c|c|}
\hline \multicolumn{10}{|c|}{ CP13 - teste 1 } \\
\hline $\begin{array}{c}\text { Patamar } \\
\mathbf{d e} \\
\text { tensão }\end{array}$ & $\begin{array}{c}\boldsymbol{F}_{\max } \\
\mathbf{( N )}\end{array}$ & $\begin{array}{c}\boldsymbol{F}_{\min } \\
(\mathbf{N})\end{array}$ & $\begin{array}{c}\boldsymbol{\sigma}_{\boldsymbol{a}} \\
(\mathbf{M P a})\end{array}$ & $\begin{array}{c}\boldsymbol{\sigma}_{\boldsymbol{m}} \\
(\mathbf{M P a})\end{array}$ & $\begin{array}{c}\boldsymbol{\sigma}_{\text {eq }} \\
(\mathbf{M P a})\end{array}$ & $\begin{array}{c}\boldsymbol{T}_{\text {estab }} \\
\left({ }^{\circ} \mathbf{C}\right)\end{array}$ & $\begin{array}{c}\boldsymbol{N}_{\text {estab }} \\
(\mathbf{c i c l o s})\end{array}$ & $\begin{array}{c}\Delta \mathbf{N i} \\
(\mathbf{c i c l o s})\end{array}$ & $\begin{array}{c}\mathbf{N}_{\text {si }} \\
(\mathbf{c i c l o s})\end{array}$ & $\begin{array}{c}\mathbf{N}_{\mathbf{f}} \\
(\mathbf{c i c l o s})\end{array}$ \\
\hline 1 & 2160 & 1661 & 5.28 & 40.46 & 12.77 & 0.81 & 964 & 964 & 964 & 36357 \\
\hline 2 & 2270 & 1765 & 5.35 & 42.73 & 14.04 & 0.98 & 2052 & 752 & 4286 & 31724 \\
\hline 3 & 2512 & 2000 & 5.42 & 47.78 & 17.63 & 1.06 & 3272 & 572 & 7093 & 30742 \\
\hline 4 & 2669 & 2125 & 5.76 & 50.76 & 21.79 & 1.17 & 4620 & 620 & 6689 & 28020 \\
\hline 5 & 2779 & 2212 & 6.00 & 52.85 & 25.65 & 1.25 & 6032 & 832 & 12732 & 29428 \\
\hline
\end{tabular}

\begin{tabular}{|c|c|c|c|c|c|c|c|c|c|c|}
\hline \multicolumn{10}{|c|}{ CP13 - teste 2 } \\
\hline $\begin{array}{c}\text { Patamar } \\
\mathbf{d e} \\
\text { tensão }\end{array}$ & $\begin{array}{c}\boldsymbol{F}_{\text {max }} \\
\mathbf{( N )}\end{array}$ & $\begin{array}{c}\boldsymbol{F}_{\min } \\
(\mathbf{N})\end{array}$ & $\begin{array}{c}\boldsymbol{\sigma}_{\boldsymbol{a}} \\
(\mathbf{M P a})\end{array}$ & $\begin{array}{c}\boldsymbol{\sigma}_{\boldsymbol{m}} \\
(\mathbf{M P a})\end{array}$ & $\begin{array}{c}\boldsymbol{\sigma}_{\text {eq }} \\
(\mathbf{M P a})\end{array}$ & $\begin{array}{c}\boldsymbol{T}_{\text {estab }} \\
\left({ }^{\circ} \mathbf{C}\right)\end{array}$ & $\begin{array}{c}\boldsymbol{N}_{\text {estab }} \\
(\mathbf{c i c l o s})\end{array}$ & $\begin{array}{c}\Delta \mathbf{N i} \\
(\mathbf{c i c l o s})\end{array}$ & $\begin{array}{c}\mathbf{N}_{\text {si }} \\
(\mathbf{c i c l o s})\end{array}$ & $\begin{array}{c}\mathbf{N}_{\mathbf{f}} \\
\text { (ciclos) }\end{array}$ \\
\hline 1 & 2300 & 1802 & 5.27 & 43.43 & 14.23 & 0.612 & 975 & 975 & 975 & 47745 \\
\hline 2 & 2725 & 2203 & 5.53 & 52.18 & 22.68 & 0.951 & 2250 & 950 & 2661 & 31710 \\
\hline 3 & 2923 & 2370 & 5.86 & 56.05 & 31.19 & 1.117 & 3289 & 589 & 3981 & 27879 \\
\hline 4 & 2984 & 2398 & 6.20 & 56.99 & 35.64 & 1.175 & 4084 & 484 & 9767 & 29489 \\
\hline
\end{tabular}




\begin{tabular}{|c|c|c|c|c|c|c|c|c|c|c|}
\hline \multicolumn{10}{|c|}{ CP13 - teste 3 } \\
\hline $\begin{array}{c}\text { Patamar } \\
\mathbf{d e} \\
\text { tensão }\end{array}$ & $\begin{array}{c}\boldsymbol{F}_{\max } \\
\mathbf{( N )}\end{array}$ & $\begin{array}{c}\boldsymbol{F}_{\min } \\
(\mathbf{N})\end{array}$ & $\begin{array}{c}\boldsymbol{\sigma}_{\boldsymbol{a}} \\
(\mathbf{M P a})\end{array}$ & $\begin{array}{c}\boldsymbol{\sigma}_{\boldsymbol{m}} \\
(\mathbf{M P a})\end{array}$ & $\begin{array}{c}\boldsymbol{\sigma}_{\text {eq }} \\
(\mathbf{M P a})\end{array}$ & $\begin{array}{c}\boldsymbol{T}_{\text {estab }} \\
\left({ }^{\circ} \mathbf{C}\right)\end{array}$ & $\begin{array}{c}\boldsymbol{N}_{\text {estab }} \\
(\mathbf{c i c l o s})\end{array}$ & $\begin{array}{c}\Delta \mathbf{N i} \\
(\mathbf{c i c l o s})\end{array}$ & $\begin{array}{c}\mathbf{N}_{\text {si }} \\
(\mathbf{c i c l o s})\end{array}$ & $\begin{array}{c}\mathbf{N}_{\mathbf{f}} \\
(\mathbf{c i c l o s})\end{array}$ \\
\hline 1 & 2417 & 1926 & 5.20 & 45.99 & 15.59 & 0.622 & 936 & 936 & 936 & 46973 \\
\hline 2 & 2693 & 2155 & 5.70 & 51.33 & 22.25 & 0.953 & 2361 & 1161 & 3337 & 31998 \\
\hline 3 & 3065 & 2514 & 5.83 & 59.07 & 40.56 & 1.064 & 2970 & 370 & 3558 & 28957 \\
\hline
\end{tabular}

\begin{tabular}{|c|c|c|c|c|c|c|c|c|c|c|}
\hline \multicolumn{10}{|c|}{ CP1 } \\
\hline $\begin{array}{c}\text { Patamar } \\
\mathbf{d e} \\
\text { tensão }\end{array}$ & $\begin{array}{c}\boldsymbol{F}_{\boldsymbol{m a x}} \\
\mathbf{( N )}\end{array}$ & $\begin{array}{c}\boldsymbol{F}_{\boldsymbol{m i n}} \\
\mathbf{( N )}\end{array}$ & $\begin{array}{c}\boldsymbol{\sigma}_{\boldsymbol{a}} \\
(\mathbf{M P a})\end{array}$ & $\begin{array}{c}\boldsymbol{\sigma}_{\boldsymbol{m}} \\
(\mathbf{M P a})\end{array}$ & $\begin{array}{c}\boldsymbol{\sigma}_{\boldsymbol{e q}} \\
(\mathbf{M P a})\end{array}$ & $\begin{array}{c}\boldsymbol{T}_{\text {estab }} \\
\left({ }^{\circ} \mathbf{C}\right)\end{array}$ & $\begin{array}{c}\boldsymbol{N}_{\text {estab }} \\
(\mathbf{c i c l o s})\end{array}$ & $\begin{array}{c}\Delta \mathbf{N i} \\
(\mathbf{c i c l o s})\end{array}$ & $\begin{array}{c}\mathbf{N}_{\mathbf{s i}} \\
(\mathbf{c i c l o s})\end{array}$ & $\begin{array}{c}\mathbf{N}_{\mathbf{f}} \\
(\mathbf{c i c l o s})\end{array}$ \\
\hline 1 & 546.00 & 175.00 & 12.01 & 3.85 & 13.49 & 0.42 & 1822 & 1822 & 1822 & 69108 \\
\hline 2 & 681.00 & 232.00 & 14.98 & 5.10 & 15.29 & 0.53 & 6948 & 1948 & 9508 & 58977 \\
\hline
\end{tabular}

\begin{tabular}{|c|c|c|c|c|c|c|c|c|c|c|}
\hline \multicolumn{10}{|c|}{ CP2 } \\
\hline $\begin{array}{c}\text { Patamar } \\
\mathbf{d e} \\
\text { tensão }\end{array}$ & $\begin{array}{c}\boldsymbol{F}_{\max } \\
\mathbf{( N )}\end{array}$ & $\begin{array}{c}\boldsymbol{F}_{\min } \\
\mathbf{( N )}\end{array}$ & $\begin{array}{c}\boldsymbol{\sigma}_{\boldsymbol{a}} \\
(\mathbf{M P a})\end{array}$ & $\begin{array}{c}\boldsymbol{\sigma}_{\boldsymbol{m}} \\
(\mathbf{M P a})\end{array}$ & $\begin{array}{c}\boldsymbol{\sigma}_{\text {eq }} \\
(\mathbf{M P a})\end{array}$ & $\begin{array}{c}\boldsymbol{T}_{\text {estab }} \\
\left({ }^{\circ} \mathbf{C}\right)\end{array}$ & $\begin{array}{c}\boldsymbol{N}_{\text {estab }} \\
(\mathbf{c i c l o s})\end{array}$ & $\begin{array}{c}\Delta \mathbf{N i} \\
(\mathbf{c i c l o s})\end{array}$ & $\begin{array}{c}\mathbf{N}_{\text {si }} \\
(\mathbf{c i c l o s})\end{array}$ & $\begin{array}{c}\mathbf{N}_{\mathbf{f}} \\
(\mathbf{c i c l o s})\end{array}$ \\
\hline 1 & 540.20 & 167.50 & 11.85 & 3.67 & 14.38 & 0.48 & 2683 & 2683 & 2683 & 61230 \\
\hline 2 & 672.10 & 240.50 & 14.74 & 5.28 & 15.73 & 0.75 & 8130 & 3130 & 8703 & 42701 \\
\hline 3 & 842.70 & 320.00 & 18.49 & 7.02 & 16.48 & 0.84 & 11545 & 1545 & 14589 & 41584 \\
\hline
\end{tabular}

\begin{tabular}{|c|c|c|c|c|c|c|c|c|c|c|}
\hline \multicolumn{10}{|c|}{$\mathbf{C P 3}$} \\
\hline $\begin{array}{c}\text { Patamar } \\
\mathbf{d e} \\
\text { tensão }\end{array}$ & $\begin{array}{c}\boldsymbol{F}_{\max } \\
(\mathbf{N})\end{array}$ & $\begin{array}{c}\boldsymbol{F}_{\min } \\
(\mathbf{N})\end{array}$ & $\begin{array}{c}\boldsymbol{\sigma}_{\boldsymbol{a}} \\
(\mathbf{M P a})\end{array}$ & $\begin{array}{c}\boldsymbol{\sigma}_{\boldsymbol{m}} \\
(\mathbf{M P a})\end{array}$ & $\begin{array}{c}\boldsymbol{\sigma}_{\text {eq }} \\
(\mathbf{M P a})\end{array}$ & $\begin{array}{c}\boldsymbol{T}_{\text {estab }} \\
\left({ }^{\circ} \mathbf{C}\right)\end{array}$ & $\begin{array}{c}\boldsymbol{N}_{\text {estab }} \\
(\mathbf{c i c l o s})\end{array}$ & $\begin{array}{c}\Delta \mathbf{N i} \\
(\mathbf{c i c l o s})\end{array}$ & $\begin{array}{c}\mathbf{N}_{\text {si }} \\
(\mathbf{c i c l o s})\end{array}$ & $\begin{array}{c}\mathbf{N}_{\mathbf{f}} \\
(\mathbf{c i c l o s})\end{array}$ \\
\hline 1 & 540.70 & 199.00 & 11.99 & 4.41 & 15.62 & 0.38 & 1542 & 1542 & 1542 & 76940 \\
\hline 2 & 672.00 & 248.00 & 14.91 & 5.50 & 16.12 & 0.50 & 3792 & 1792 & 7623 & 62069 \\
\hline 3 & 829.00 & 321.00 & 18.39 & 7.12 & 20.61 & 0.60 & 7730 & 1731 & 9018 & 52581 \\
\hline 4 & 1162.00 & 529.00 & 25.78 & 11.73 & 23.96 & 0.76 & 9814 & 1815 & 8678 & 42359 \\
\hline 5 & 1330.00 & 633.00 & 29.50 & 14.04 & 25.72 & 0.87 & 10733 & 734 & 5914 & 36260 \\
\hline
\end{tabular}

\begin{tabular}{|c|c|c|c|c|c|c|c|c|c|c|}
\hline \multicolumn{10}{|c|}{ CP5 } \\
\hline $\begin{array}{c}\text { Patamar } \\
\mathbf{d e} \\
\text { tensão }\end{array}$ & $\begin{array}{c}\boldsymbol{F}_{\boldsymbol{m a x}} \\
\mathbf{( N )}\end{array}$ & $\begin{array}{c}\boldsymbol{F}_{\min } \\
\mathbf{( N )}\end{array}$ & $\begin{array}{c}\boldsymbol{\sigma}_{\boldsymbol{a}} \\
(\mathbf{M P a})\end{array}$ & $\begin{array}{c}\boldsymbol{\sigma}_{\boldsymbol{m}} \\
(\mathbf{M P a})\end{array}$ & $\begin{array}{c}\boldsymbol{\sigma}_{\boldsymbol{e q}} \\
(\mathbf{M P a})\end{array}$ & $\begin{array}{c}\boldsymbol{T}_{\text {estab }} \\
\left({ }^{\circ} \mathbf{C}\right)\end{array}$ & $\begin{array}{c}\boldsymbol{N}_{\text {estab }} \\
(\mathbf{c i c l o s})\end{array}$ & $\begin{array}{c}\Delta \mathbf{N i} \\
(\mathbf{c i c l o s})\end{array}$ & $\begin{array}{c}\mathbf{N}_{\mathbf{s i}} \\
(\mathbf{c i c l o s})\end{array}$ & $\begin{array}{c}\mathbf{N}_{\mathbf{f}} \\
(\mathbf{c i c l o s})\end{array}$ \\
\hline 1 & 571.10 & 174.20 & 12.39 & 3.78 & 13.68 & 0.55 & 742 & 742 & 742 & 53246 \\
\hline 2 & 687.60 & 238.20 & 14.92 & 5.17 & 15.13 & 0.66 & 5700 & 700 & 3971 & 45537 \\
\hline
\end{tabular}

A Figura abaixo apresenta a curva SN do policarbonato medida experimentalmente utilizando a termografia e o método de Risitano. 
Os pontos são plotados na escala $\log \log$ e são ajustados por uma relação potencial, a equação resultante foi: $\mathrm{NS}^{1.492}=3.33 * 10^{6}$, enquanto a ajustada em [5] foi igual a $\mathrm{NS}^{1.316}=1.75^{*} 10^{6}$.

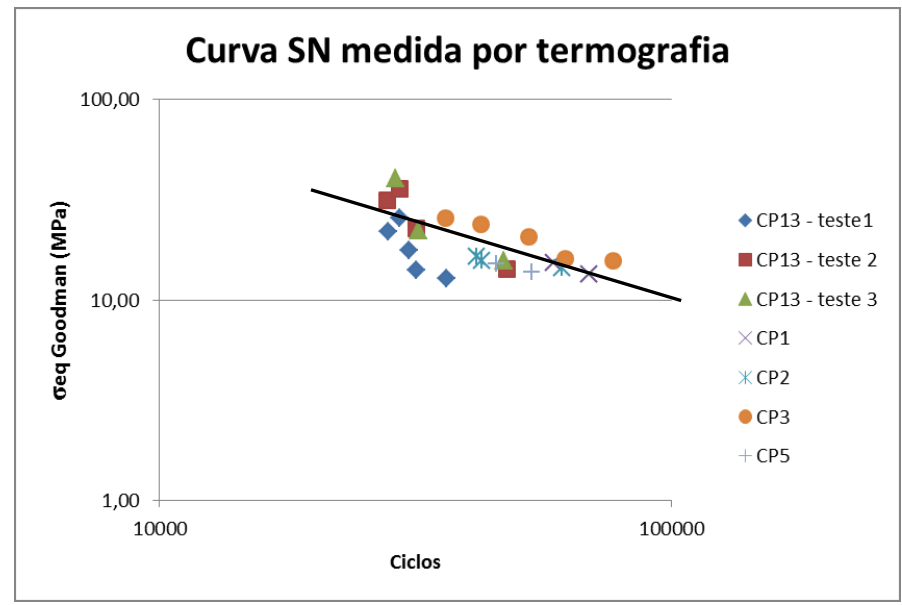

Figura 5.1: Curva SN medida por termografia para diferentes testes

\subsection{Determinação da Curva SN Utilizando o Método Tradicional}

Foram realizados 5 testes com um nível de tensão constante em cada teste para obtenção da curva SN do material. A relação entre as tensões atuantes em cada teste e número de ciclos até a falha é apresentado na tabela 5.2.

Tabela 5.2: Tensão equivalente e número de ciclos até a falha para cada CP.

\begin{tabular}{|c|c|c|}
\hline $\mathbf{C P}$ & $\boldsymbol{\sigma}_{\boldsymbol{e q}}(\mathbf{M P a})$ & $\boldsymbol{N}_{\boldsymbol{f}}(\mathbf{C i c l o s})$ \\
\hline 6 & 8.86 & $100000 \rightarrow$ \\
\hline 7 & 10.10 & 63778 \\
\hline 8 & 12.87 & 44201 \\
\hline 9 & 12.12 & 44531 \\
\hline 10 & 24.43 & 15862 \\
\hline
\end{tabular}

A Figura abaixo compara as curvas $\mathrm{SN}$ medida experimentalmente por duas técnicas diferentes (Risitano e SN tradicional) e a obtida na literatura, [5]. Observa-se que ambas tem um comportamento similar. 


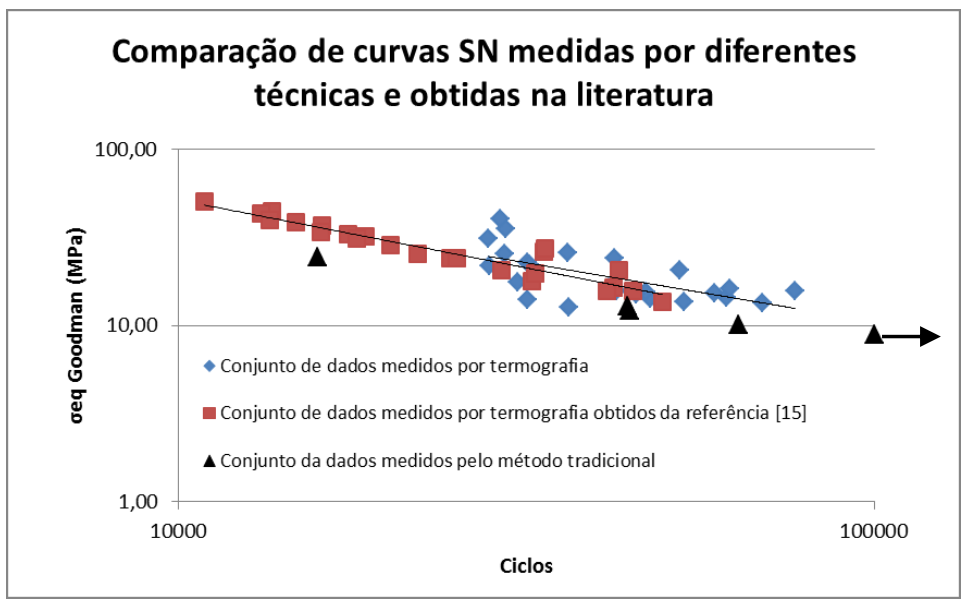

Figura 5.2: Comparação curvas SN

Ajustando uma curva SN média, Figura abaixo, com todos os pontos disponíveis, obtém-se a seguinte equação para descrever o comportamento do material: $\mathrm{NS}^{1.414}=5.47 * 10^{6}$.

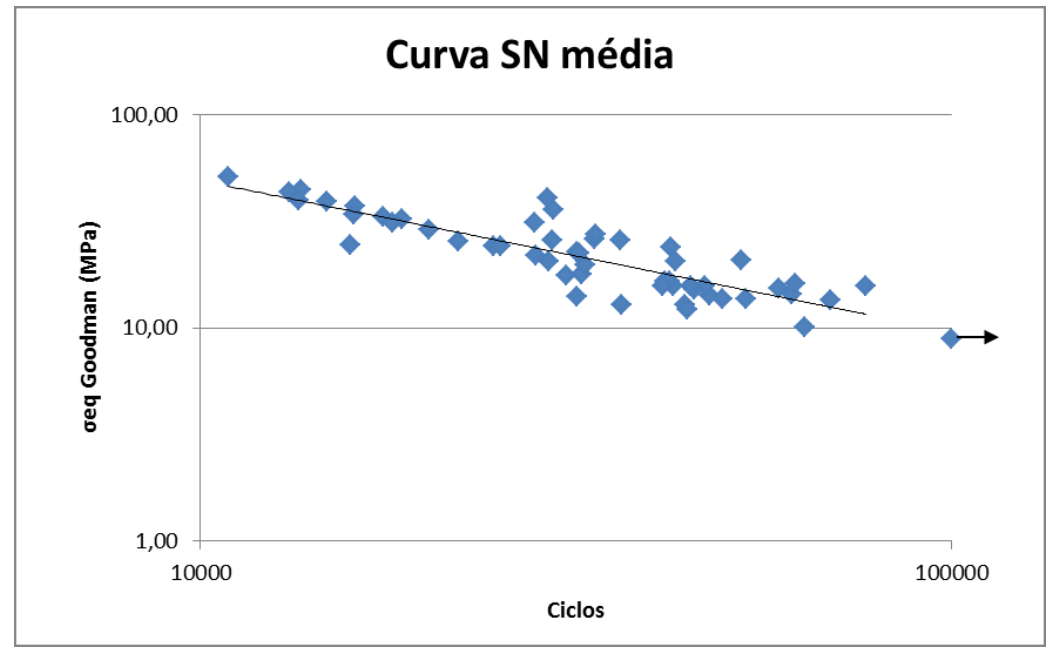

Figura 5.3: Média de todas as curvas SN medidas em diferentes técnicas 


\section{Conclusão}

Esse trabalho se baseou na determinação da curva de Wöhler (curva $\mathrm{SN}$ ) e do limite de fadiga do policarbonato através do uso da termografia. Através do método foi possível realizar ensaios muito mais rápidos e com menor custo que os métodos tradicionais. Além de o método não precisar ser prolongado até a ruptura do corpo de prova. Algumas melhorias foram feitas em comparação a trabalhos antigos, como o uso do isolamento térmico, que trouxe maior confiabilidade para os resultados encontrados.

Diversos testes foram feitos com o objetivo de comparar os resultados e saber da exatidão do método utilizado e os resultados estiveram sempre dentro do esperado. Apesar de os resultados terem sido bons é preciso desenvolver um método melhor para encontrar as temperaturas estabilizadas, visto que o critério utilizado pelo autor foi um critério arbitrário visual, não sendo possível criar um padrão para determinação do mesmo.

Conclui-se que o uso da termografia tem grande potencial para estudo de fadiga e que o método, por não ser muito antigo, ainda tem muito a evoluir. 


\section{Referência Bibliográfica}

[1] CASTRO. J. T. P. D.; MEGGiOLARO. M. A.: "Fadiga - Técnicas e Práticas de Dimensionamento Estrutural sob Cargas Reais de Serviço. Volume I - Iniciação de Trincas." CreateSpace. 2009.

[2] EL HADDAD. M.H.. TOPPER. T.H. AND SMITH. K.N. "Prediction of nonpropagating cracks". Engineering Fracture Mechanics v.11. 1979

[3] LA ROSA G.. RISITANO A.. "Thermographic methodology for rapid determination of the fatigue limit of materials and mechanical components". International Journal of Fatigue. Vol. 22. pp. 65-73. 2000.

[4] FARGIONE G.. GERACI A.. LA ROSA G.. RISITANO A.. "Rapid determination of the fatigue curve by the thermographic method". International Journal of Fatigue. Vol. 24. pp. 11-19. 2002.

[5] VIEIRA. R.B.. "Thermography Applied to the Study of Fatigue in Polycarbonate ". Dissertacao de mestrado. PUC-Rio. 2016.

[6] ASTM STP 91A "A Guide for Fatigue Testing and the Statistical Analysis of Fatigue Data”. 2016

[7] SINCLAIR. G. M. AND T. J. DOLAN. "Effect of Stress Amplitude on Statistical Variability in Fatigue Life of 75S-T6 Aluminum Alloy." Transactions of the American Society of Mechanical Engineers. 75:867-872. 1953.

[8] American Society for Testing and Materials. "Standard Practice for Statistical Analysis of Linear or Linearized Stress-Life (S-N) and Strain-Life $(\varepsilon-N)$ Fatigue Data." ASTM Standard E739-80. Aug 1980.

[9]ANNIS. CHARLES. "Runouts: Analyzing Fatigue Data with Runouts.”

StatisticalEngineering.com (website). 2004.

[10] POLLAK. D. R.. "Analysis of methods for determining high cycle fatigue strength of a material with investigation of ti-6al-4v gigacycle fatigue behavior “. Master dissertation. Department of the Air Force Air University. 2005

[11] LUIZ EDUARDO MIRANDA J. RODRIGUES. Disponível em:

$<$ http://www.engbrasil.eng.br/pp/em/aula11.pdf > . Acessado em 25/11/2016.

[12] RANDALL (TY) POLLAK. 2006_A simulation-based investigation of the staircase method. 
[13] DIXON. W.J.. MOOD. A.M.. 1948. A method for obtaining and analyzing sensitivity data. J. Am. Stat. Assoc. 43. 109-126.

[14] Galeria de imagens da câmera termográfica FLIR T1K. Disponível em: $<$ http://www.flir.com.br/instruments/content/?id=70502>. Acessado em 14/12/2016.

[15] PLANCK. M.. LUDWIG. K.E. em: Verhandl. Dtsc. Phys. Ges. 2 (1900) pp.202204.

[16] Estudo pratico energia irradiada. Disponível em:

$<\underline{\text { http://www.estudopratico.com.br/energia-irradiada-lei-do-deslocamento-e-irradiacao- }}$ termica>. acessado em 07/12/2016.

[17] BARBER J. R.. "ELASTICITY”. Solid Mechanics and its Applications Vol. 172. Chapter 14. p. 219-225. 2010.

[18] DULIEU-BARTON. J.M.. "Introduction to thermoelastic stress analysis". Strain. pp. 35-39. May. 1999.

[19] FLIR A655sc High-Resolution Science Grade LWIR Camera. Disponivel em: $<$ http://www.flir.com/science/display/?id=46802 > . acessado em 03/12/2016. [20] ALVA J.G.C.. "Controle por aprendizado neuro-fuzzy aplicado a uma máquina de fadiga atuada por um músculo pneumático”. PhD Thesis. Pontifícia Universidade Católica do Rio de Janeiro. Departamento de Engenharia Mecânica. 2013.

[21] MCKEEN L.W.. "Fatigue \& Tribological Properties of Plastics \& Elastomers". 2nd edition. William Andrew. 2009. 